\title{
Características fisico-químicas e reológicas de amido de milho (Zea mays L.) de pipoca crioulo
}

\author{
Physical chemicals and rheologicals characterization of corn starch (Zea mays l.) landraces
}

popcorn

Caracterización física química y reológica de almidón de maíz (Zea mays l.) palomero criollo

Recebido: 04/10/2021 | Revisado: 14/10/2021 | Aceito: 15/10/2021 | Publicado: 20/10/2021

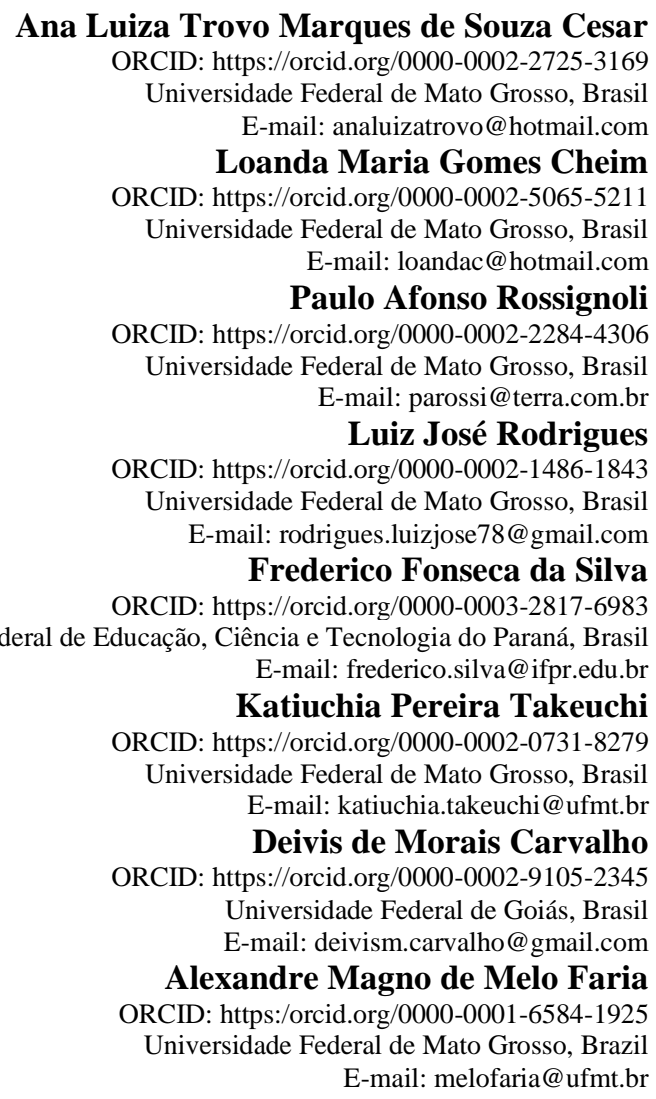

\begin{abstract}
Resumo
O amido é uma substância considerada biodegradável e bastante utilizada na indústria alimentícia já que é de baixo custo e abundante na natureza. Propriedades como a gelatinização, retrogradação, o poder de inchamento, a solubilidade e a capacidade de retenção de água podem interferir na elaboração de alimentos. Assim, o presente trabalho objetivou extrair o amido de milho (Zea Mays L.) pipoca crioulo por moagem úmida bem como determinar sua composição proximal, além de avaliar seu comportamento reológico e propriedades térmicas sob diferentes condições de processamento. O rendimento da extração do amido de milho de pipoca (Zea Mays L.) crioulo foi de $6,3 \%$. Suas características são comuns a muitos amidos, mas também diferente como, por exemplo, a baixa acidez que favorece o seu uso para o aumento da viscosidade em outros produtos industrializados. Os tamanhos e formas dos grânulos verificados através da MEV (Microscopia Eletrônica de Varredura) justificam seu comportamento viscoelástico e características reológicas. Da mesma forma, podem ter contribuído para a sua perda de massa juntamente com os teores de proteína e lipídeos. A concentração de lipídio também foi decisiva na gelatinização do amido do presente estudo. A espectroscopia no infravermelho comprovou que o amido de milho pipoca (Zea Mays L.) crioulo comportou-se tipicamente como outros amidos, bem como a sua cristalinidade. Assim o milho crioulo para extração desse amido é de uma espécie crioula e potencialmente cultivável pela agricultura familiar e em sistema agroecológico, incorporando características sustentáveis.
\end{abstract}

Palavras-chave: Amido de milho crioulo; Comportamento reológico; Gelatinização; Rendimento. 


\begin{abstract}
Starch is a substance considered biodegradable and widely used in the food industry as it is low cost and abundant in nature. Properties such as gelatinization, retrogradation, swelling power, solubility and water holding capacity can interfere with food preparation. Thus, the present work aimed to extract cornstarch (Zea Mays L.) creole popcorn by wet grinding as well as to determine its proximal composition, in addition to evaluating its rheological behavior and thermal properties under different processing conditions. The extraction yield of starch from colored popcorn (Zea Mays L.) corn was $6.3 \%$. Its characteristics are common to many starches, but also different, such as the low acidity that favors its use to increase viscosity in other industrialized products. The sizes and shapes of the granules verified by SEM (Scanning Electron Microscopy) justify their viscoelastic behavior and rheological characteristics. Likewise, they may have contributed to their loss of mass along with their protein and lipid levels. The lipid concentration was also decisive in the gelatinization of the starch in the present study. Infrared spectroscopy confirmed that colored popcorn starch (Zea Mays L.) typically behaved like other starches, as well as its crystallinity. Thus, the Creole corn for the extraction of this starch is of a Creole species and potentially cultivable by family farming and in an agroecological system, incorporating sustainable characteristics.
\end{abstract}

Keywords: Creole cornstarch; Rheological behavior; Gelatinization; Yield.

\title{
Resumen
}

El almidón es una sustancia considerada biodegradable y ampliamente utilizada en la industria alimentaria, ya que es de bajo costo y abundante en la naturaleza. Propiedades como la gelatinización, la retrogradación, el poder de hinchamiento, la solubilidad y la capacidad de retención de agua pueden interferir con la preparación de los alimentos. Así, el presente trabajo tuvo como objetivo extraer palomeros criollas de almidón de maíz (Zea Mays L.) mediante molienda húmeda, así como determinar su composición proximal, además de evaluar su comportamiento reológico y propiedades térmicas bajo diferentes condiciones de procesamiento. El rendimiento de extracción de almidón de maíz de palomitas de maíz de colores (Zea Mays L.) fue del 6,3\%. Sus características son comunes a muchos almidones, pero también diferentes, como la baja acidez que favorece su uso para aumentar la viscosidad en otros productos industrializados. Los tamaños y formas de los gránulos verificados por SEM (Microscopía Electrónica de Barrido) justifican su comportamiento viscoelástico y características reológicas. Asimismo, pueden haber contribuido a su pérdida de masa junto con sus niveles de proteínas y lípidos. La concentración de lípidos también fue decisiva en la gelatinización del almidón en el presente estudio. La espectroscopia infrarroja confirmó que el almidón de palomitas de maíz de colores (Zea Mays L.) se comportaba típicamente como otros almidones, así como su cristalinidad. Así, el maíz criollo para la extracción de este almidón es de una especie criolla y potencialmente cultivable por agricultura familiar y en un sistema agroecológico, incorporando características sustentables.

Palabras clave: Fécula de maíz criolla; Comportamiento reológico; Gelatinización; Producir.

\section{Introdução}

O milho é considerado uma das maiores culturas agrícolas utilizadas para consumo, tendo cerca de $50 \%$ da sua produção relacionada ao consumo humano ou ao processamento industrial. O aumento do seu uso, tanto na alimentação humana quanto na animal, deu-se especialmente pelo seu valor nutricional relacionado a energia, valor protéico, fibroso e oleaginoso (Abimilho, 2021). O amido é a principal fonte energética do milho sendo considerada biodegradável e inovadora, já que é de baixo custo e abundante na natureza, tendo no milho, sua principal fonte de origem vegetal. Além disso, ele apresenta o caráter potencial para cultivo em sistema agroecológico pela agricultura familiar, tão difundido atualmente, já que se degrada sem gerar resíduos ao meio ambiente. Tal preocupação vem se tornando cada dia mais importante devido não só pelas questões ambientais, mas sobretudo pelo uso irracional de recursos não renováveis, gerando altos custos de produção e descarte de resíduo orgânico e inorgânico, o que vem impulsionando nos últimos anos o desenvolvimento de novas tecnologias (Trire et al., 2004, Diamantino, 2013). Na indústria alimentícia, o amido destaca-se por conferir textura a produtos industrializados, principalmente de panificação por ter características espessantes e fornecedor de sólidos para suspensões(Ascheri et al., 2010; Cavalcanti et al., 2011; Wang et al., 2016). Os amidos cerosos ou waxy, apresentam características como menor temperatura de gelatinização, menor viscosidade, e menores evidências de retrogradação (Jiranuntakul et al., 2011).

Além da sua origem, a forma de extração do amido influência no seu uso e aplicabilidade industrial, além de interferir no seu comportamento reológico e nas propriedades físico-químicas e funcionais (Xiao et al., 2011; Correia et al., 2012; Correia et al., 2013). A proporção entre os dois principais componentes do amido, amilose e amilopectina, bem como o 
comprimento da cadeia são influenciadas pela fonte botânica e condições climáticas de estocagem do material de origem do amido, influenciando as características específicas da pasta e a funcionalidade do amido (Zhu et al., 2017). Da mesma forma, propriedades térmicas e de decomposição das pastas de amido são relevantes para avaliar a utilidade desse amido. Esta utilização poder ser restringida de acordo com as características físico-químicas desse amido, pois seus grânulos são insolúveis em água, o que demanda um cozimento para intensificação das propriedades anteriormente citadas. Após esse cozimento o amido também pode tender à perda da viscosidade e espessamento quando resfriado. Diante de um amido oriundo de um milho crioulo de colocação escura, acredita-se que suas características aqui citadas podem diferir dos tradicionais e já conhecidos. Acrescido a isso, a possibilidade de cultivo e replicação do mesmo pela agricultura familiar pode possibilitar seu uso de forma mais intensa por essas comunidades, trazendo ganhos para a mesma, além de poderem ter um produto diferenciado no mercado. Logo, estudos reológicos do amido são bastante úteis no esclarecimento de processos como estabilidade de emulsão e extrusão para posterior aplicabilidade desse amido em subprodutos (Albano, 2012). Nesse sentido, o presente trabalho teve como objetivo extrair amido de milho (Zea Mays L.) pipoca crioulo por moagem úmida e como essa técnica influencia na sua composição proximal, além de avaliar o comportamento reológico e as propriedades térmicas sob diferentes situações de temperatura, frequência, pressão e escoamento. Espera-se que se obtenham características favoráveis ao uso desse amido pela indústria de alimentos e até mesmo agregar valor nutritivo aos produtos que o contenham.

\section{Material e Métodos}

O amido de milho foi extraído de milho de Pipoca (Zea mayz L.) crioulo cultivado na Fazenda Experimental da Universidade Federal de Mato Grosso (UFMT), localizada no município de Santo Antônio do Leverger (MT, Brasil, 15², 51'57' $5,56^{\circ} 4^{\prime} 37^{\prime}$ 'W) no ano de 2017. Após a colheita, o milho foi levado para a Faculdade de Nutrição (FANUT) da UFMT e se verificou que o teor de umidade dos grãos, se encontrava em 18,9\%. O milho foi, então, debulhado e os grãos foram espalhados em mesa de inox e mantidos em temperatura ambiente. Quando atingiram a umidade ideal (em torno de 13\%), foram separados, conforme a sua coloração, pesados e embalados à vácuo em saco plástico de polietileno de $15 \mu \mathrm{m}$ e armazenados sob congelamento onde foram mantidos até a realização das análises. Além disso, o milho após estudo foi considerado G3 (azul) que se caracteriza por apresentar predominantemente grãos pontiagudos, com exceção das variedades RSX6A, MGP3B, MGY1D e PC (Pipoca Crioulo), que possuem grãos redondos. Isso quer dizer que as variedades atualmente coletadas foram compreendidas dentro da amplitude de variabilidade fenotípica das antigas variedades, não apresentando características que possam diferenciá-las o suficiente para indicá-las como "novas" raças, mas sim de interesse comercial. Dessa forma, foram consideradas as seguintes variedades atualmente conservadas no Brasil e no Uruguai: i) pipocas pontiagudas do Brasil, pertencentes à raça Avatí Pichingá, conhecida localmente como milho Alho; ii) pipocas redondas do Brasil, que pertencentes à raça Avatí Pichingá Ihú, conhecida genericamente como "Pipoca"; e iii) pipocas redondas do Uruguai pertencentes à raça Pipoca redondo, reconhecida localmente como "Pipoca", "Picoca". Desta forma a variedade PC pertence à raça Avatí Pichingá Ihú (Cheim et al., 2021).

\section{Extração do amido}

A Extração do amido de milho de pipoca (Zea mayz L.) crioulo ocorreu em agosto de 2019 na Universidade de Cuiabá (UNIC), campus Beira Rio I, conforme metodologia de extração úmida apresentada por Wang Y. J. et al., (2006) com adequações. Primeiramente a matéria prima foi pesada $(6,25 \mathrm{~kg})$, selecionada e limpa, para descarte dos grãos que apresentavam algum aspecto visual de degradação física ou química; lavada em água corrente, para remoção das sujidades e particulados indesejáveis; e, em seguida, lavada com água destilada. Os grãos foram deixados de molho com água destilada por 
$16 \pm 2$ horas em estufa de secagem com circulação de ar (Solidsteel, modelo SSDc 64L, Piracicaba, Brasil) a 50 ${ }^{\circ} \mathrm{C}$. Em seguida, foram macerados em liquidificador (Mallory, modelo aurus 1000 Preto 900w, São Paulo, Brasil) colocando-se em média $200 \mathrm{~g}$ de grãos/1000 mL de água destilada, por um período de 10 minutos, para desintegração máxima das células e liberação dos grânulos de amido. O produto, chamado leite de amido, contem a proteína do milho concentrada. Esse produto foi então filtrado em peneira granular de aço inox 8x2 com malha de 60 tyler, para separação das fibras do material solúvel. Nessa primeira filtragem, foi adicionado mais $10 \mathrm{~mL}$ de água destilada para facilitar e agilizar o processo. $\mathrm{O}$ filtrado foi posto em repouso para decantar aproximadamente $12 \pm 2$ horas a $5^{\circ} \mathrm{C}$ em Geladeira BOD (Solidsteel, digital tipo geladeira 80 Litros SolidSteel 13072, Piracicaba, Brasil). Após esse período, desprezou-se o sobrenadante (cerca de $750 \mathrm{~mL}$ ) e o amido decantado foi ressuspenso em água destilada (mesma quantidade do sobrenadante desprezado) e filtrado em peneira granular de aço inox $8 \times 2$ com malha de 200 Tyler (ABNT, 2010) e colocado para decantar novamente por $12 \pm 2$ horas a $5^{\circ} \mathrm{C}$ na temperatura de $5^{\circ} \mathrm{C}$. O líquido sobrenadante foi novamente descartado, e o amido obtido foi colocado em tubos Falcon com capacidade de $15 \mathrm{~mL}$ e centrifugado a 3.000 rpm por 15 minutos em Centrífuga Digital de bancada Refrigerada com Velocidade ajustável (Kasvi, modelo K14-4000, São José dos Pinhais, Brasil) descartando-se o sobrenadante, e sendo seco em estufa já citada com circulação de ar a $40^{\circ} \mathrm{C}$. Após a secagem, o resíduo gerado desta separação o corn gluten meal, produto final principal, o amido seco foi então macerado em almofariz para homogeneização da granulometria. Após isso, o amido foi colocado em sacos plásticos estéreis, armazenado e mantido em dessecador à temperatura ambiente até o momento das análises.

\section{Rendimento}

O rendimento da extração do amido do milho foi determinado pela massa de amido final dividida pela massa do milho crioulo utilizado para extração e expresso em porcentagem, conforme equação 1, seguida por (Julyana et al., 2018).

$$
\text { Rendimento }(\%)=\frac{\text { Massadoamidoobtido }(g) \times 100}{\text { PesodoGrãoinicial }(g)}
$$

\section{Composição proximal do amido}

A umidade foi verificada pela secagem em estufa (Biopar ${ }^{\circledR}$, modelo S80SD, Restinga, Brasil) a $110^{\circ} \mathrm{C}$ de acordo com a metodologia ( $\mathrm{n}^{\circ}$ 925.10) adaptada da AOAC (2010). As cinzas foram determinadas por incineração da amostra em mufla da marca Stecno ${ }^{\circledR}$ Fornos e Equipamentos, modelo 115 a $550^{\circ} \mathrm{C}$ até obter peso constante conforme descrito no método $\left(\mathrm{n}^{\circ}\right.$ 923.03) da AOAC, (2010). Na análise de atividade de água utilizou-se Analisador de Atividade de Água por ponto de orvalho com controle interno da temperatura da amostra (Aqualab®, modelo 4te, EUA), que segue a metodologia oficial de A.O.A.C 978.18. Para determinação do extrato etéreo das amostras de amido de milho, foi utilizado o método de extração direta em Soxhlet, conforme preconiza o INSTITUTO ADOLFO LUTZ, (2008) (nº 032/IV). Já o teor de proteína bruta foi determinado pelo método de Kjeldahl (Lutz, 2008) - n $\mathrm{n}^{\circ}$ 037/IV) e o percentual de carboidratos totais foi calculado por diferença, subtraindo-se de 100 os teores encontrados para umidade, extrato etéreo, proteínas e cinzas.

Também foi identificado o teor de fibra alimentar total (solúvel e insolúvel), de acordo com a metodologia adaptada número 32-05 da AACC (Ha et al., 2000) e número 985.29 da AOAC (2010).

\section{$p H$}

Essa determinação foi feita utilizando dois tipos de amido: um comercial da marca Maisena ${ }^{\circledR}$ e o de milho crioulo. Para tanto foram separadas as amostras contendo $10 \mathrm{~g}$ de cada amido, adicionada $100 \mathrm{~mL}$ de água destilada sendo este conteúdo agitado por 30 minutos, permanecendo então, em repouso por 10 minutos. A determinação do pH foi feita através de potenciômetro digital de bancada $\left(B e l^{\circledR}, p h s 3 w\right.$, Monza, Itália) 
Cor

A cor foi determinada também dos dois amidos já citados, utilizando um colorímetro (Konica Minolta, modelo CM700d, Japan), conforme metodologia descrita pela AOAC (2012). Para croma (C*) e para o ângulo de tonalidade $\left(H^{*}\right)$, seguiu-se Macdougal (1994) e Moritz (2011), usando as coordenadas de luminosidade (L*), teor de vermelho (a*) e intensidade de amarelo $\left(b^{*}\right)$, sendo:

- $\quad L^{*}$ mede a variação da luminosidade entre o preto (0) e o branco (100) corresponde ao claro e ao escuro.

- $\quad a^{*} E$ É uma das coordenadas de cromaticidade, e define a cor vermelha para valores positivos e a cor verde para valores negativos, onde o verde fica próximo de -60 e o vermelho de +60

- $\quad b^{*} E$ É a coordenada de cromaticidade, que define a cor amarela para valores positivos (+60) e a cor azul (-60) para valores negativos. Esses dados foram obtidos nas determinações colorimétricas, através das equações 2 e 3 :

$$
\begin{aligned}
& \text { 2. } C *=\sqrt{\left(a^{*}\right)^{2}+\left(b^{*}\right)^{2}} \\
& \text { 3. } \quad H=\arctan \left(\frac{b *}{a *}\right)
\end{aligned}
$$

\section{Microscopia eletrônica de varredura (MEV)}

As micrografias dos amidos foram obtidas em um microscópio eletrônico de varredura de alta resolução (MEV) (modelo Jeol JSM 7100F, Tokio, Japão )com tensão de aceleração de elétrons de 0.5kV no modo de detecção de elétrons secundários (SED). Os grânulos foram colocados sobre suportes metálicos (stubs), e dispersos em fita adesiva dupla face para fixação e depósito de ouro em Sputter para a análise. As fotomicrografias foram obtidas através de um aumento de 300 a 1000 vezes.

\section{Análise termogravimétrica (DTA/TG)}

Os termogramas foram obtidos pela técnica de Análise Térmica Diferencial e Termogravimétrica, usando um equipamento Shimadzu (modelo DTG-60H, Tokio, Japão). As medidas foram realizadas no intervalo de temperaturas de 28 a $800{ }^{\circ} \mathrm{C}$, com taxa de aquecimento de $10^{\circ} \mathrm{C} / \mathrm{min}$, fluxo de nitrogênio de $200 \mathrm{~mL} / \mathrm{min}$, em cadinhos de platina de $70 \mu \mathrm{L}$.

\section{Espectrofotometria infravermelho (FTIR)}

Os espectros de absorção no Infravermelho foram adquiridos utilizando-se a técnica de transmissão em pastilha de $\mathrm{KBr}$ contendo $1 \%$ da amostra, em um espectrofotômetro com Transformada de Fourier Bruker Vertex 70. Os espectros da amostra foram adquiridos na faixa espectral de $4000-400 \mathrm{~cm}^{-1}$, com uma resolução de $4 \mathrm{~cm}^{-1}$, sendo cada espectro o resultado da média de 64 medidas.

\section{Difração de raios $X$}

As medidas de difração de raios X (DRX) foram realizadas do em um difratômetro (modelo Bruker D8 Discover, Ettlingen, Germany). Utilizou-se radiação monocromática de um tubo com anodo de cobre acoplado a um monocromador Johansson para Kal operando em $40 \mathrm{kV}$ e $40 \mathrm{~mA}$, configuração Bragg-Brentano 0-20, detector unidimensional Lynxeyeß, intervalo de 20 de $4^{\circ}$ a $50^{\circ}$, com passo de $0,01^{\circ}$. As amostras foram mantidas em rotação de 15 rpm durante as medidas. 


\section{Análises reológicas}

Preparo das Amostras

Ensaios reológicos em cisalhamento estacionário e em cisalhamento oscilatório com baixa amplitude de deformação foram realizados em reômetro (Anton PaarPhysica, MCR 101, Ostfildern, Germany) utilizando geometria de placas paralelas de $50 \mathrm{~mm}$ de diâmetro com $1 \mathrm{~mm}$ de gap. As suspensões foram preparadas com 3\% de amido em água destilada. As amostras foram colocadas na placa sem gelatinizar ou gelatinizada, dependendo do tipo de análise a ser feita. Todos os testes foram realizados em (duplicata) com uma amostra nova em cada repetição. Os testes foram realizados com o amido de milho crioulo e amido de milho comercial (da marca Maisena®) adquirido no comércio local.

\section{Cisalhamento em estado estacionário}

\section{Curvas de escoamento}

No estudo reológico em cisalhamento estacionário foi utilizado o reômetro já citado com distância entre as placas paralelas (gap) de $1 \mathrm{~mm}$. O comportamento da suspensão de amido crioulo não gelatinizado foi avaliado obtendo-se curvas de escoamento, a partir de 3 rampas de tensão de cisalhamento em função de taxa de deformação $\left(1 \mathrm{a} 100 \mathrm{~s}^{-1}\right)$ : ascendente (rampa 1), descendente (rampa 2) e ascendente (rampa 3) na temperatura de $25^{\circ} \mathrm{C}$. O tempo de cada corrida para essa análise foi de cerca de 20 minutos e a varredura ocorreu em taxa linear.

\section{Varredura de Temperatura}

Para varredura de temperatura, a amostra preparada a 3\% em água destilada não gelatinizada foi introduzida a $25^{\circ} \mathrm{C}$ na placa com sistema Peltier de controle de temperatura, aquecida rapidamente até $50^{\circ} \mathrm{C}$ onde a corrida foi iniciada até alcançar $90^{\circ} \mathrm{C}$, com taxa de aquecimento linear de $2^{\circ} \mathrm{C} /$ minuto e taxa de deformação de $10 \mathrm{~s}^{-1}$.

\section{Cisalhamento em estado oscilatório}

\section{Varredura de deformação}

Foram avaliadas as propriedades viscoelásticas dos géis de amido de milho crioulo a 3\% de concentração e térmicas através de medidas reológicas em cisalhamento oscilatório para classificar o seu comportamento em função dos espectros mecânicos. Para a varredura de deformação, a amostra foi pré gelatinizada a $90^{\circ} \mathrm{C} / 30 \mathrm{~min}$ em agitação magnética e depois resfriada a temperatura ambiente. Inicialmente foi realizada uma varredura em deformação crescente $(0,01$ até $50 \%)$ para verificação da região de viscoelasticidade linear, mantendo-se a frequência de oscilação constante em $1 \mathrm{~Hz}$ e temperatura constante de $25^{\circ} \mathrm{C}$.

\section{Varreduras de frequência}

As varreduras de frequência foram realizadas nas amostras pré gelatinizadas, na faixa de frequência entre $0,1 \mathrm{a} 10 \mathrm{~Hz}$ utilizando as taxas de deformação de 1\%, obtidas nos resultados prévios da Varredura de Deformação. Os módulos de armazenamento (G') e de dissipação (G'), ângulo de fase e viscosidade complexa foram avaliados a $25^{\circ} \mathrm{C}$ buscando identificar o comportamento mecânico dos géis de amido.

\section{Varredura de temperatura ou cura isotérmica}

O comportamento viscoelástico em função da temperatura de cisalhamento foi feito para determinar a cinética de gelatinização do amido de milho crioulo. A suspensão a3\% não gelatinizada foi colocada no aparelho configurado para 
trabalhar com deformação de $1 \%$ e frequência de $1 \mathrm{~Hz}$ por 20 minutos. A dispersão foi colocada na placa Peltier a $25^{\circ} \mathrm{C}$ e aquecida até $50^{\circ} \mathrm{C}$. A partir daí a análise foi iniciada com uma taxa de aquecimento de $2^{\circ} \mathrm{C}$ por minuto até atingir $90^{\circ} \mathrm{C}$.

\section{Varredura de tempo}

Ao final da análise de varredura de temperatura ou cura isotérmica a amostra não removida do equipamento foi resfriada em repouso até a temperatura indicada na análise de varredura de temperatura como o início do processo de gelatinização $+5^{\circ} \mathrm{C}\left(73,5\right.$ ou $\left.74,6^{\circ} \mathrm{C}\right)$. A varredura de tempo foi então realizada com uma deformação de $1 \%$ e frequência de 1 $\mathrm{Hz}$ por 900 segundos (15 minutos).

\section{Análise estatística dos dados}

As análises da composição proximal e cor foram feitas em quintuplicatas e os resultados expressos através da média e desvio padrão. As análises de MEV foram retiradas de 7 micrografias com aumentos que variavam de 300 a 1000 vezes. Para as análises de DTA/TG, FTIR, Difração por Raios-X foram realizadas somente com o milho crioulo e em duplicata. Nas análises reológicas foram utilizados os dois amidos (crioulo e comercial) e feitas duas repetições para o Cisalhamento Estacionário e Oscilatório, sendo que os resultados foram tratados em programa Excel na função Solver.

\section{Resultados e Discussão}

Através do método de moagem úmida do milho, que objetiva o aumento da eficácia na separação das partes que compõe o grão de milho, gérmen, endosperma e pericarpo, para a obtenção do amido de milho, gera um rendimento de, aproximadamente 68-73\% do total dos grãos conforme citado por Nguyen et al., (1998) e Cargill, (2019). A extração do amido de milho pipoca crioulo deste ensaio resultou em um pó fino, de coloração cinza a lilás claro e inodoro, com rendimento de extração foi 6,3\% em relação ao total de milho utilizado, um rendimento considerado baixo quando comparado ao método tradicional utilizando também a via úmida, mas com uso de substâncias consideradas aditivos. Essas substâncias são passiveis de controle pela legislação brasileira dos níveis residuais nos produtos finais, tais como o bissulfito de cálcio e sódio, dióxido de enxofre. Esses aditivos são utilizados pela indústria para, entre outras coisas, retardar as reações de escurecimentos e aumentar o rendimento da extração (Resolução-RDC No 263, de 22 de Setembro de 2005). Em contrapartida, essas substâncias representam perigo à saúde humana já que há relatos de que indivíduos com intolerância a esses elementos podem apresentar crises de asma, reações cutâneas, dores de cabeça, diarreias, confusões mentais, hipotensão, choque anafilático, dores abdominais, náuseas, tonturas, entre outros efeitos (García-Gavín et al., 2012). Zhuang et al., (2013) afirmou que os subprodutos oriundos da moagem úmida do milho, os chamados corn glutens, contém cerca de $60 \%$ em massa protéica, com uma diminuição na concentração de aminoácidos essenciais. É este o quesito que diferencia o glúten de milho obtido a partir dessa moagem úmida, do glúten de outros cereais, como o trigo composto pelo complexo gliadina e glutenina. Esse amido pode ser utilizado na indústria com substituições de 25 a 50\% em relação à farinha de trigo convencionalmente usada, podendo melhorar a digestibilidade desses produtos, sendo bastante indicadas também para o consumo infantil e de idosos, principalmente àqueles intolerantes ao glúten, os chamados celíacos (Franco et al., 2018).

O milho pipoca (Zea mayz L.) utilizado para extração do amido nesse experimento foi cultivado e colhido de forma mais natural possível, sem o uso de qualquer defensivo agrícola ou maquinário. Da mesma forma, no processo de extração procurou-se também não utilizar nenhum agente químico que pudesse alterar, não só a sua composição, mas também retirar a característica agroecológica deste produto. Conclui-se que os resultados alcançados se justificam pela ausência de substância 
química em seu processo de extração. Isso é benéfico para a saúde humana e também facilita o uso da metodologia de extração por pequenos agricultores que podem replicar os procedimentos em nível artesanal.

Com relação às análises físico-químicas e composição proximal do amido de milho pipoca (Zea Mays L.) crioulo, a média dos valores e desvio padrão encontrados estão apresentados na Tabela $1 . \mathrm{O}$ amido é composto em sua maioria por carboidratos, o que se pode confirmar através dos dados apresentados. Porém, constituintes de menor concentração como lipídeos, proteínas, cinzas/ resíduos minerais estão também presentes. Teores elevados de proteína influenciariam no processo de gelatinização do amido, pois competiriam junto com o amido pela água (Candido et al., 2017).

Quando se compara os dados do presente amido com os do amido de milho cru da Tabela de Composição de Alimentos (TACO), verifica-se que temos um amido com um valor de proteína $\left(5,10 \mathrm{~g} / 100 \mathrm{~g}^{-1}\right)$, de fibras $\left(0,92 \mathrm{~g} / 100 \mathrm{~g}^{-1}\right)$, de cinzas $(1,99$ $\left.\mathrm{g} / 100 \mathrm{~g}^{-1}\right)$ e de lipídeos $\left(2,05 \mathrm{~g} / 100 \mathrm{~g}^{-1}\right)$. Quando transformamos esses valores para a porção de amido de milho determinada pela legislação brasileira (20g ou 1 colher de sopa), temos o oferecimento de 76,09Kcal, correspondendo a 3,80\% de uma dieta de 2000kca 1 (UNICAMP, 2011). Dessa forma, não podemos afirmar que se trata de um alimento protéico e nem fonte de fibras. No entanto, independente da composição nutricional, não se pode negar que se utilizado, não só na composição de alimentos industrializados, terá esse valor nutritivo adicionado a esse alimento. Além disso, por apresentarem porcentagem de proteínas e fibras, o presente amido pode ser capaz de proporcionar melhor textura quando adicionado como ingrediente (Belhadi et al., 2013).

Tabela 1: Análise física química e Valor Calórico do amido de milho pipoca (Zea Mays L.) crioulo e tradicional.

\begin{tabular}{|c|c|c|c|c|}
\hline PARÂMETROS & $\begin{array}{c}\text { VALOR } \\
\text { MÉDIO* } \\
\text { (Amido de } \\
\text { milho } \\
\text { crioulo) }\end{array}$ & $\mathrm{CV}(\%)$ & $\begin{array}{c}\text { (Universidade } \\
\text { Estadual de } \\
\text { Campinas } \\
\text { UNICAMP, } \\
2011 \text { ) } \\
\text { (Amido de } \\
\text { milho) } \\
\end{array}$ & $\begin{array}{l}\text { (Weber et } \\
\text { al., 2009) }\end{array}$ \\
\hline Umidade $\left(\mathrm{g.100g}^{-1}\right)$ & $6,20 \pm 0,15$ & 2,4 & $12 \%$ & $13 \%$ \\
\hline pH & $5,11 \pm 0,01$ & 0,2 & - & - \\
\hline Proteína $\left(\mathrm{g} .100 \mathrm{~g}^{-1}\right)$ & $5,10 \pm 0,15$ & 2,9 & 1 & $0,05 \pm 0,01$ \\
\hline Lipídeos (g.100g $\left.{ }^{-1}\right)$ & $2,05 \pm 0,07$ & 3,4 & $\mathrm{Tr}^{* *}$ & $0,12 \pm 0,07$ \\
\hline Cinzas $\left(\mathrm{g} .100 \mathrm{~g}^{-1}\right)$ & $0,32 \pm 0,13$ & & 0,1 & - \\
\hline Fibra Alimentar (S+I) $\left({\left.\mathrm{g} .100 g^{-1}\right)}^{-1}\right.$ & $0,92 \pm 0,05$ & 5,4 & 0,7 & - \\
\hline Fração Glicídica $\left({\left.\mathrm{g} .100 \mathrm{~g}^{-1}\right)}^{-1}\right.$ & $85,41 \pm 0,18$ & 0,2 & 87 & - \\
\hline Atividade água $\left(\mathbf{a}_{\mathrm{w}}\right)$ & 0,21 & - & - & - \\
\hline Valor Calórico (kcal.100g-1) & 380,48 & - & 364 & - \\
\hline
\end{tabular}

*Média \pm desvio padrão ( $=5$ ) / matéria integral de amido de milho crioulo

** Traços (Tr)

Fonte: Autores.

O amido estudado comportou-se próximo ao amido comercial em relação aos teores de carboidrato e fibra alimentar. Já o teor de cinzas apresentou-se alto em relação a amido de milho tradicional. Conforme a NEPA (2011), a cada 100g de amido de milho cru, apresenta 0,1g de cinzas. Segundo Gwirtz \& Garcia-Casal, (2014) em meio aos minerais encontrados na composição de subprodutos da industrialização do milho o cálcio, fósforo, magnésio, potássio e selênio são os que se apresentam em maior concentração. Dessa forma, a partir desse valor, podemos cogitar que alimentos ou preparações que contenham o presente amido tenham uma viabilidade em relação à complementação de nutrientes minerais nos mesmos. No 
entanto, análises específicas desses minerais precisariam ser feitas para confirmar a presença desses nutrientes. Dessa forma, obteve-se um valor interessante de proteína que pode agregar valor aos produtos que o contenham. Já quando se compara aos valores da tabela citada ao da fécula de mandioca, verifica-se que o amido de milho crioulo também se apresenta com menor energia ( $k c a l 100 \mathrm{~g}^{-1}$ ), maior quantidade protéica e valores próximos de carboidratos e fibra alimentar. As proteínas influenciam na gelatinização do amido através da formação de complexos sobre a superfície do grânulo prevenindo a liberação de amilose e amilopectina a partir dos mesmos. Assim, a temperatura de gelatinização do amido aumenta e a natureza hidrofílica das proteínas disponibiliza a água para intumescer os grânulos de amido (Saliba Rodrigues et al., 2014). Proteínas e amidos desempenham papel fundamental na estrutura, textura e estabilidade dos alimentos. No entanto, como eles são raramente encontrados isolados, o conhecimento do desempenho de suas misturas é de grande interesse industrial (Bello-Pérez et al., 2000).

A partir dos resultados obtidos na caracterização dos amidos de milho crioulo, verificou-se que o teor de umidade e o pH encontram-se baixos. A maioria dos amidos nativos apresentam pH próximo da neutralidade. Em muitos trabalhos é relatado que a viscosidade da pasta de amido decresce na presença de ácidos (Pensiri Sriburi \& Hill, 2000; P. Sriburi et al., 1999; Vallès-Pàmies et al., 1997). O pH tem relação direta com a natureza do amido nativo (aquele que não passou por nenhum tipo de modificação). $\mathrm{O}$ amido do presente estudo apresentou valores de $\mathrm{pH}$ mais básicos, sugerindo que sua utilização em formulações de produtos alimentícios pode interferir na viscosidade do mesmo. Aliado a isso, temos uma atividade de água $(A w)$ correspondente ao intervalo de 0,2 a 0,4 . Nesta faixa de $A w$, a estabilidade do alimento é a mais alta. Nesta região, não é preciso o uso de conservantes para controlar, por exemplo, o crescimento de microrganismos e a qualidade do produto também não são afetados pelo escurecimento não-enzimático (Araújo, 2004). Assim, verifica-se que o amido estudado apresenta uma $A w$ ótima para manter a estabilidade dos alimentos que o tiverem em sua composição, já que uma das propriedades dele é a capacidade de formar uma pasta ou gel viscoso na presença de água por aquecimento, que o torna adequado para várias utilizações em indústrias alimentares e não-alimentares.

A utilização do amido na indústria alimentícia tem-se dado devido às propriedades espessantes e gelificante, por serem bons reguladores e estabilizadores de textura, além de atuarem como ingrediente para retenção de água (Castro, 2019). O teor de umidade encontrado no amido do presente trabalho encontra-se dentro das especificações recomendadas pela legislação brasileira para amidos comerciais, a qual recomenda teor de água máximo de 15\% para amido (Brasil, 2005). Mahmood et al., (2017) afirmaram que a presença de lipídios e proteínas influencia o sabor do amido. Sendo assim, o uso do amido do presente estudo na indústria alimentícia pode interferir no sabor dos alimentos. Conforme Foschia et al. (2013) o uso de subprodutos no desenvolvimento de novos alimentos além de ser uma provável fonte de antioxidantes, provenientes da composição do grão, como os carotenóides, pode ser um forte método para adicionar fibras alimentares como ingredientes funcionais e coadjuvantes de tecnologia abrandando o efeitos de sinérese, pela elevação da absorção de água e ausência de retrogradação, estabilização de emulsões de alimentos com altas concentrações de gorduras, modificação de textura e viscosidade.

Quando relacionado à cor em alimentos, atributo importante e decisório tanto para o consumidor como para a indústria alimentícia, percebe-se que o amido estudado difere do comercial. Os parâmetros utilizados constata-se que o $\mathrm{L}^{*}$ indica a luminosidade (quão clara ou escura é a amostra) e o a* e b*, são as coordenadas cromáticas, sendo o a* a coordenada vermelho/verde ( $+\mathrm{a}$ indica vermelho e $-\mathrm{a}$ indica verde) e o $\mathrm{b}^{*}$ indica a coordenada amarelo / azul ( $+\mathrm{b}$ indica amarelo e $-\mathrm{b}$ indica azul).Os resultados positivos para $\mathrm{a}^{*}(3,98 \pm 0,13)$ e $\mathrm{b}^{*}(8,03 \pm 0,18)$, caracterizam a predominância da cor amarela. Já a luminosidade não foi tão intensa, já que os valores de $L^{*}$ ficaram próximos de $100(70,31 \pm 0,54)$ indicando que o amido se aproxima mais do branco. Em relação aos parâmetros utilizados de cor, L*( luminosidade), tonalidade da cor (h) e saturação da cor $\left(C^{*}\right)$ obtidos, a luminosidade foi alta, já que os valores de $L^{*}$ ficaram próximos de $100(70,31 \pm 0,54)$ indicando que o 
amido se aproxima mais do branco. O Hue $\left(^{\circ}\right)$, com valores próximos de $64(\approx 63,6)$ indica que o amido estudado apresenta um tom alaranjado (entre o amarelo e vermelho). Tal coloração pode indicar presença de carotenóides, mas novas análises precisam ser feitas. Para (Uenojo et al., 2007) os carotenóides fixam-se em componentes vegetais através de ligações covalentes e com proteínas. Possivelmente as maiores concentrações protéicas do amido estudado $(5,10 \pm 0,15 \mathrm{~g})$ permitiram que a ligação de pigmentos carotenóides do mesmo seja maior. A presença da cor amarelada desta matéria prima possibilita a promoção de pigmentação atraente a produtos e conseqüentemente maior aceitação.

Em relação às imagens dos amidos obtidas através da MEV (microscopia eletrônica de varredura) estão apresentadas nas Figuras 1, onde se podem observar as formas e tamanho dos grânulos (aproximadamente $10 \mu \mathrm{m}$ ), tanto com 300 vezes de aumento quanto 1000 vezes. Através da MEV, podem-se ter informações acerca da superfície dos grânulos, incluindo tamanho e a forma dos mesmos. Esses fatores são considerados de suma importância na determinação de usos potenciais de amidos. Amidos com tamanhos pequenos (cerca de 2,0 $\mu$ m) podem ser utilizados no lugar da gordura devido ao seu tamanho ser semelhante ao dos lipídeos (Leonel, 2007).

Já em relação aos formatos, os grânulos apresentaram uma forma poliédrica, com uma superfície às vezes lisa, às vezes rugosa apresentando uma espécie de concavidade e sem rachaduras, caracterizando uma matriz proteica densa. Alguns grânulos apresentaram-se com forma arredondada, o que pode ser devido ao alto teor de amilose, reportado por (Weber et al., 2009).

Figura 1: Micrografias do Amido de milho pipoca (Zea Mays L.) crioulo.

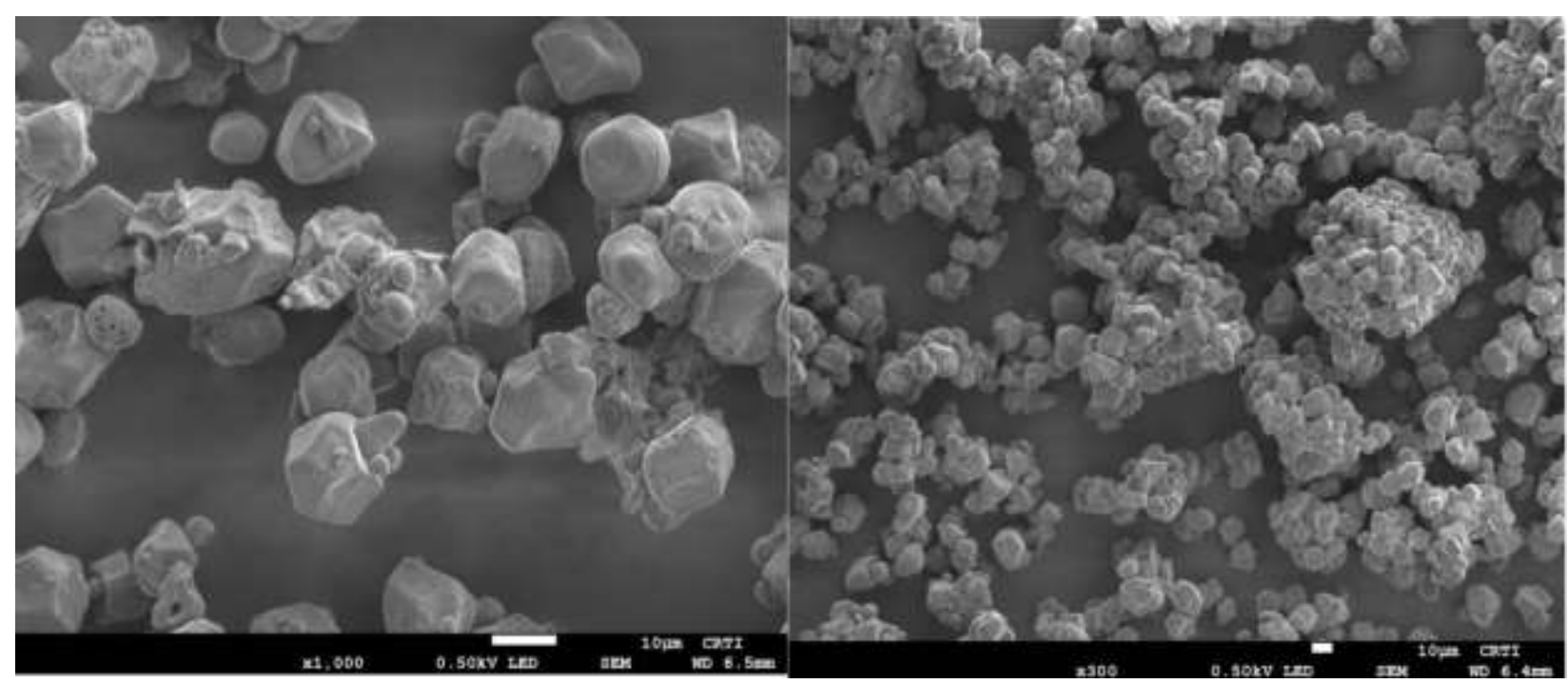

Fonte: CRTI.

As diferenças no tamanho dos grânulos de amidos influenciam nas suas características térmicas e nas propriedades de pasta, bem como na qualidade do produto processado. Superfícies de amido lisas com ausência de fissuras demonstram a pureza no processo de extração do mesmo, porém as características morfológicas podem variar de acordo com a cultivar vegetal, estágio de crescimento da planta, condições ambientais e purificação (Oyeyinka \& Oyeyinka, 2018). O tamanho de partícula é um quesito decisivo nas reações bioquímicas, já que afeta expressivamente as propriedades físico-químicas, pois aumenta a área de superfície das amostras (Asmeda et al., 2016). Tudo isso leva a crer que a ausência do uso de qualquer reagente na extração do amido de milho crioulo resultou em um produto com características satisfatórias para uso na indústria alimentícia (melhorador das propriedades físico-químicas dos alimentos que os contenha). Segundo Kaur et al., (2016) a temperatura de gelatinização dos grânulos de amido pode estar sujeito da organização estrutural dos aglomerados de 
amilopectina. O tamanho dos cristais, a estrutura polimórfica e a energia livre de reação afetam inteiramente o processo de gelatinização do amido. A temperatura de pico de gelatinização conforme Marques, (2016) possibilita uma noção qualitativa na mensuração da cristalinidade do amido presente nas amostras por meio da noção do tamanho das cadeias de dupla hélice. Para cereais como milho e arroz, a temperatura relatada se apresenta em maiores valores, pois as estruturas granulares são mais rígidas e há a presença de lipídios em sua composição (Singh et al., 2009).

As técnicas TG e DTG foram utilizadas para estudar a estabilidade e decomposição térmica do amido de milho de pipoca (Zea Mays L.) crioulo em função da perda de massa quando submetido a uma variação de temperatura. Essas técnicas são importantes para avaliar o comportamento molecular da substância, sob determinadas temperaturas a que podem ser submetidas durante o processamento dos alimentos já que alinham a perda de massa para o usuário/indústria. Através das curvas termogravimétricas, apresentadas na Figura 2, demonstraram que houve 3 (três) episódios importantes, tendo início do processo de perda de massa quando o sistema atingiu a temperatura de $45,39^{\circ} \mathrm{C}$, ou seja, momento em que a amostra deixou de ser estável termicamente e iniciou a liberação de substâncias voláteis associada ao pico endotérmico a $102,53{ }^{\circ} \mathrm{C}$ e é atribuída à desidratação inicial. Após isso, um episódio brusco de perda de massa ocorrido à temperatura de $295,32{ }^{\circ} \mathrm{C}$, sendo que essa perda se estabilizou a partir dos $450{ }^{\circ} \mathrm{C}$. Partindo de uma média de temperatura entre as maiores perdas, a massa se manteve estável indicando que o produto ou subprodutos que o contenham, podem ser processados em temperaturas menores que $300^{\circ} \mathrm{C}$, sem prejuízo das suas características.

Figura 2: Curva termogravimétrica e derivada do amido de milho.

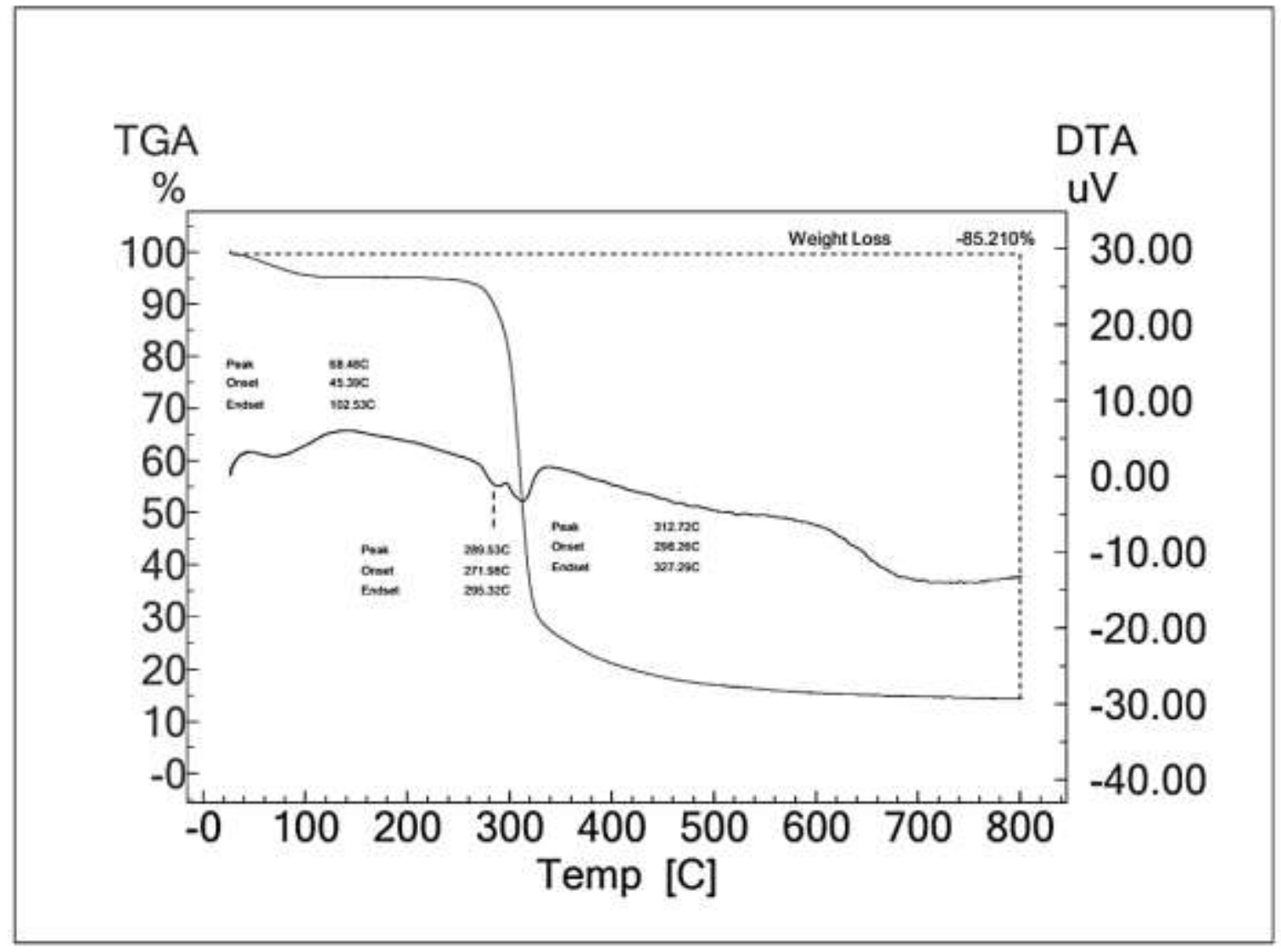

Fonte: CRTI. 
Da mesma forma, houve a desidratação em uma etapa (que durou até cerca de $45^{\circ} \mathrm{C}$ mencionados) e decomposição também em uma etapa, comportamento esse, normal a amidos de milho quando submetidos ao calor. Yonemoto, (2006) relatou em seu estudo que o poder de inchamento de amidos, está mais associado com a estrutura do grânulo e composição química, do que com o conteúdo de lipídio e do tamanho do grânulo. Quando verificamos o teor de lipídeos do presente estudo $(2,05 \pm 0,07)$, podemos concluir que as temperaturas de gelatinização justificam serem altas. Assim, após o término dos eventos verificou-se que houve uma perda total de cerca de $85 \%$ de massa do amido de milho crioulo, porcentagem esta comum a amidos tradicionais.

A espectroscopia no infravermelho (FTIR) tem sido usada devido à confiabilidade em relação à caracterização, identificação e quantificação da estrutura da amostra analisada. Além disso, esta técnica permite também a determinação de vibrações em comprimentos de ondas relacionados às interações do amido. O espectro de infravermelho do amido de milho pipoca (Zea Mays L.) crioulo está estabelecido na Figura 3.

O espectro de FTIR representa um comportamento típico do amido, descrito na literatura (Pavlovic \& Brandao, 2003; Wolkers et al., 2004; Fringant et al., 1996). A banda larga na região de 3400-3000 observada a $3401 \mathrm{~cm}-1$ corresponde à absorção dos grupos hidroxilas do amido. Bandas de absorção a aproximadamente $2930 \mathrm{~cm}-1$ e $2058 \mathrm{~cm}-1$ indicam estiramento das ligações C-H. As bandas de absorção em 1651 cm-1 e 1459-1420 cm-1 correspondem à água ligada a C-C e C-O-H, respectivamente. A posição da banda relativa à água residual é dependente da cristalinidade do polissacarídeo. Em estudos sobre a cristalinidade de dissacarídeo foi relatado o aparecimento de uma banda de absorção de água a $1685 \mathrm{~cm}$, indicando a presença de fortes ligações de hidrogênio. Bandas localizadas a aproximadamente $1370 \mathrm{~cm}-1$, 1158 cm-1 e 930 cm-1 são designadas como vibrações associadas com grupos C-OH (Wolkers et al., 2004). Os grânulos de amido por serem estruturas semicristalinas podem ser classificados por difração de raios-X em dois padrões principais: A e B e um intermediário C, resultantes da variação do conteúdo de água e do empacotamento em dupla hélice das cadeias ramificadas. Estes padrões de cristalinidade para amidos no estado nativo são variáveis de acordo com as fontes vegetais (Riley et al., 2006; Buléon et al., 1998). 
Figura 3: Espectros na região do infravermelho médio $\left(4.000-400 \mathrm{~cm}^{-1}\right)$ das amostras de amidos de milho de pipoca crioulo.

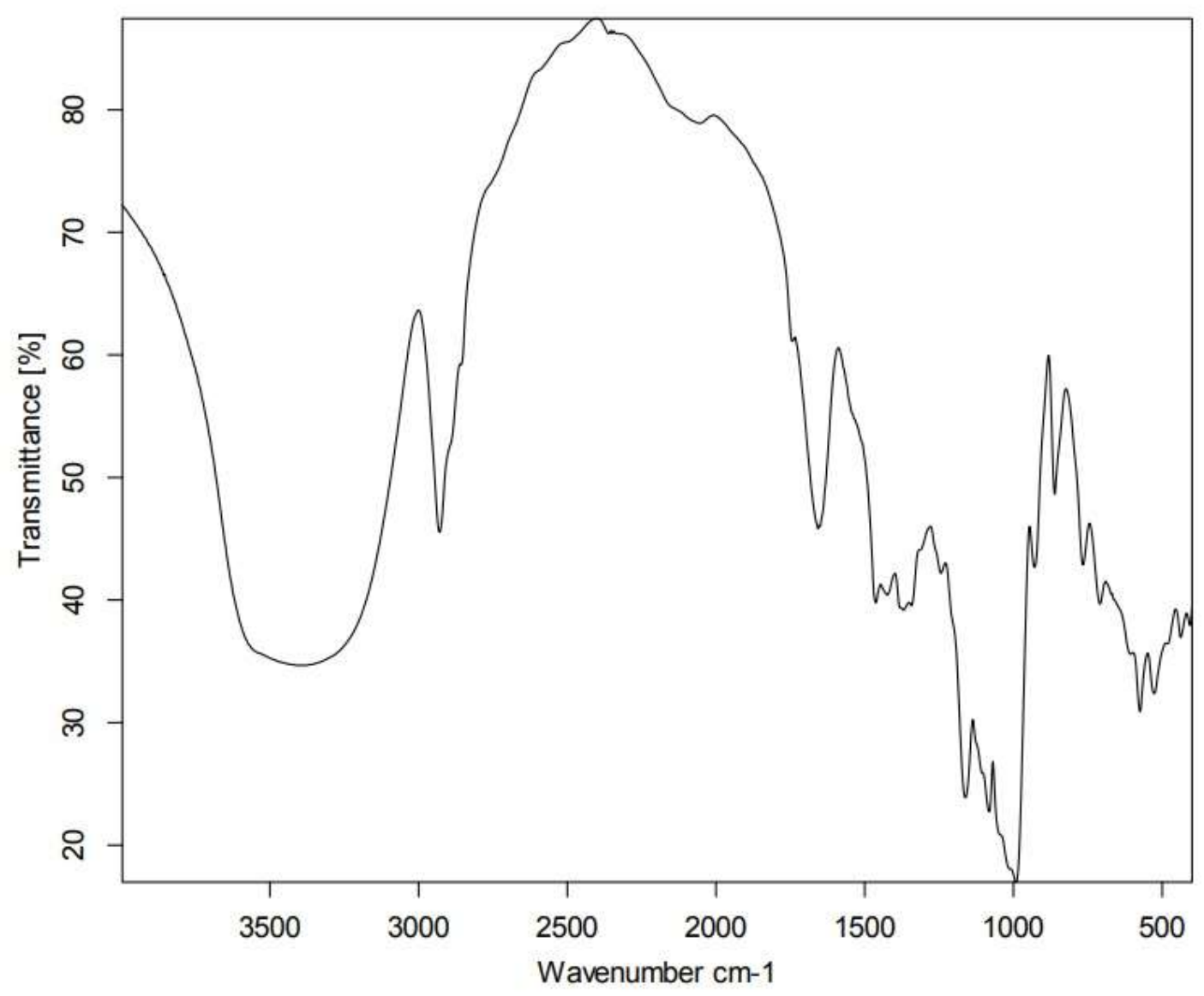

Fonte: CRTI.

O padrão A, que é o padrão do amido de milho, é caracterizado por ligações com duplas hélices fortemente empacotadas em arranjo monoclínico, tem uma estrutura relativamente compacta com baixa concentração de água, resultando em uma conformação altamente cristalina. Estudos relatam que o amido de milho nativo, apresenta uma cristalinidade por volta de 40\% (Ji \& Yu, 2018). A Figura 4 mostra o difratograma do amido de milho estudado, demonstrando que o presente amido apresenta cristalinidade do tipo A, com picos em $15^{\circ} \mathrm{C}, 18^{\circ} \mathrm{C}, 19^{\circ} \mathrm{C}$ e $23^{\circ} \mathrm{C}$. Os espectros são apresentados considerandose a região de 900 a $1300 \mathrm{~cm}^{1}$, que revela a presença de grupamentos carbonila nas amostras. O amido é amplamente utilizado como ingrediente espessante em vários produtos, tais como, produtos à base de leite, molhos, sobremesas, sopas, maioneses e alimentos semiprontos. Devido a isso, conhecer o seu comportamento reológico é muito importante. A viscosidade pode ser afetada por algumas variáveis, tais como, taxa de deformação, temperatura, concentração, pressão e tempo de cisalhamento. A temperatura de gelatinização é influenciada pelas forças de ligações no grânulo. De acordo com cada espécie podemos ter diferenças que vão da composição do grânulo como conteúdo de fósforo, enzimas, razão amilose /amilopectina, concentrações de lipídios e proteínas, estrutura molecular da amilopectina, morfologia e tamanhos dos grânulos do amido. O amido de milho tradicional geralmente apresenta uma viscosidade da pasta de médio a baixa, uma curta textura da pasta, uma opacividade dessa pasta, além de um grau alto de retrogradação (Teixeira, 2016). 
Figura 4: Difratograma do amido de milho de pipoca (Zea Mays L.) crioulo.

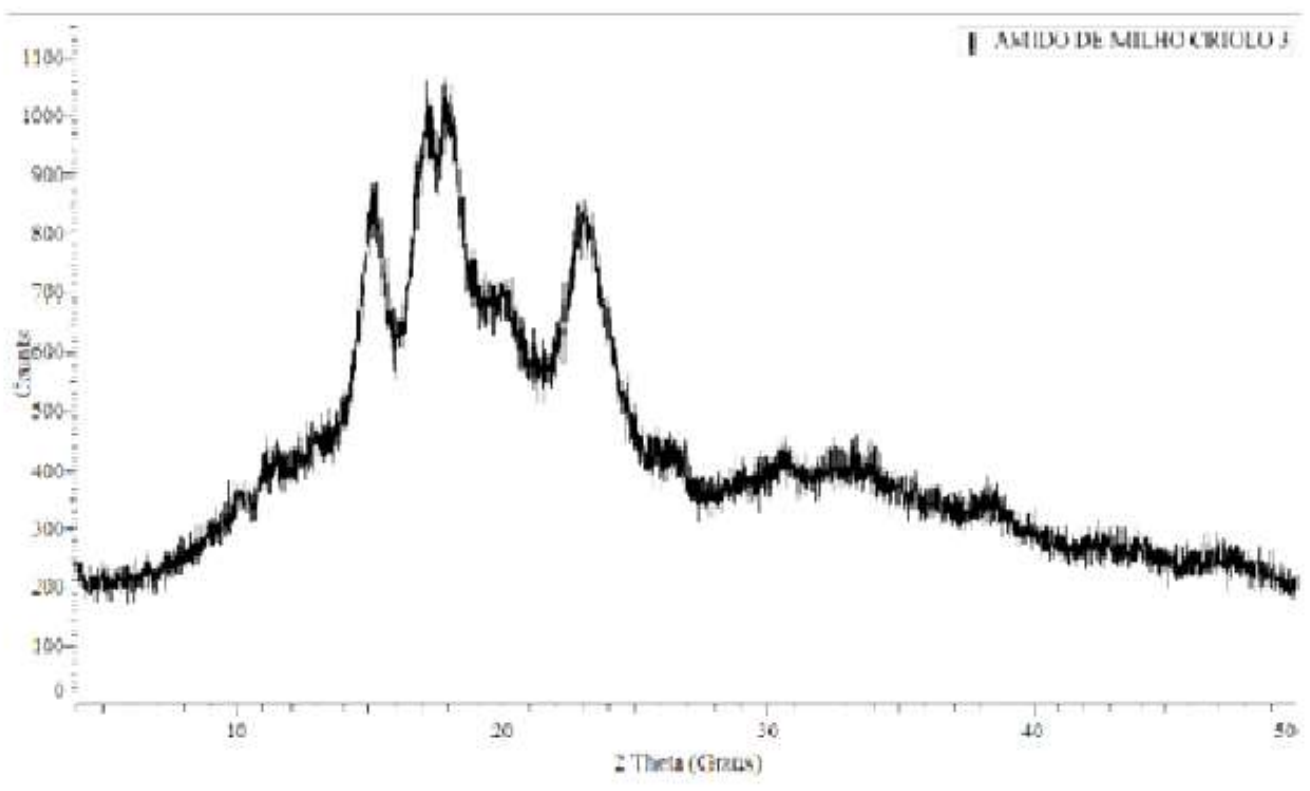

Fonte: CRTI.

\section{Comportamento reológico em altas deformações}

A viscosidade em relação à temperatura pode ser observada na Figura 5. Nas dispersões foram observadas que ambos os amidos permaneceram estáveis até cerca de $70{ }^{\circ} \mathrm{C}$. Após isso, houve um aumento substancial da viscosidade, sendo que a dispersão do amido de milho de pipoca (Zea Mays L.) crioulo atingiu valores superiores ( $\mathrm{\eta}>0,05)$ ao de amido comercial $(\eta=0,045)$. A temperatura necessária para rompimento dos grãos de amido é de aproximadamente $92{ }^{\circ} \mathrm{C}$. Todavia, a literatura não indica o tempo necessário para que todos os grãos se rompam sob o efeito de tal temperatura (Song, 2004).

\section{Comportamento reológico em baixas deformações}

O estudo do comportamento reológico de produtos é importante atualmente não somente para o dimensionamento das operações unitárias como misturas e trocas de calor mas também para otimizar a produção desses alimentos e seus processos (Piergiovanni \& Jarboe, 2016). No presente trabalho o comportamento elástico (G') e viscoelástico (G") do amido, demonstraram que os módulos de armazenamento ( $\left.G^{\prime}\right)$ e dissipação ( $\left.G^{\prime \prime}\right)$ com a frequência oscilatória, oferece informação acerca do caráter viscoelástico do sistema. Géis em que G’> G’, são qualificados como géis verdadeiros ou elásticos. Quando o comportamento ocorre de forma contrária, $G^{\prime}<G^{\prime}$, os mesmos são caracterizados como géis viscosos. Ao analisar os gráficos de varredura de freqüência (Figura 6) dos géis formados pelo amido de milho pipoca (Zea Mays L.) crioulo e amido de milho comercial, verifica-se que G' foi maior que $\mathrm{G}^{\prime \prime}$, a $25^{\circ} \mathrm{C}$, sendo então classificados como verdadeiros, ou seja, são mais elásticos que os géis formados pelo amido convencional, o que também pode ser conferido na Figura 5.

Ao analisar as Curvas de Fluxo de solubilidade (Figura 7) verifica-se que ambos os amidos tiveram a sua viscosidade mantida à medida que se aumentava a taxa de deformação do sistema, sendo que o amido comercial no início do processo apresentou um aumento da viscosidade acima do que verificado para o amido de pipoca crioulo. No entanto, após cerca de 10 segundos, ambos se comportaram de maneira semelhante. Já em relação à taxa de cisalhamento relacionada à taxa de deformação os dois amidos apresentaram comportamento semelhante: à medida que se aumentou a pressão, aumentou o cisalhamento. As curvas de fluxo exibiram um comportamento de afinamento por cisalhamento, caracterizada pela diminuição da quantidade aparente de viscosidade com taxas de cisalhamento crescentes, conforme se é esperado para amidos submetidos 
a esses efeitos. Essa situação em relação à viscosidade pode ser devido à concentração de amido utilizada (3\%). Autores relatam que dispersões com concentração mais altas, o emaranhado de moléculas é maior trazendo uma viscosidade mais intensa e conseqüentemente um comportamento frente a diferentes deformações (Sopade et al., 2004).

Figura 5: Viscosidade em relação a temperatura do amido de milho de pipoca (Zea Mays L.) crioulo e de amido de milho comercial $^{\circledR}$ sob taxa de deformação de $10 \mathrm{~s}^{-1}$.

\section{Curvas de Aquecimento - Viscosidade}

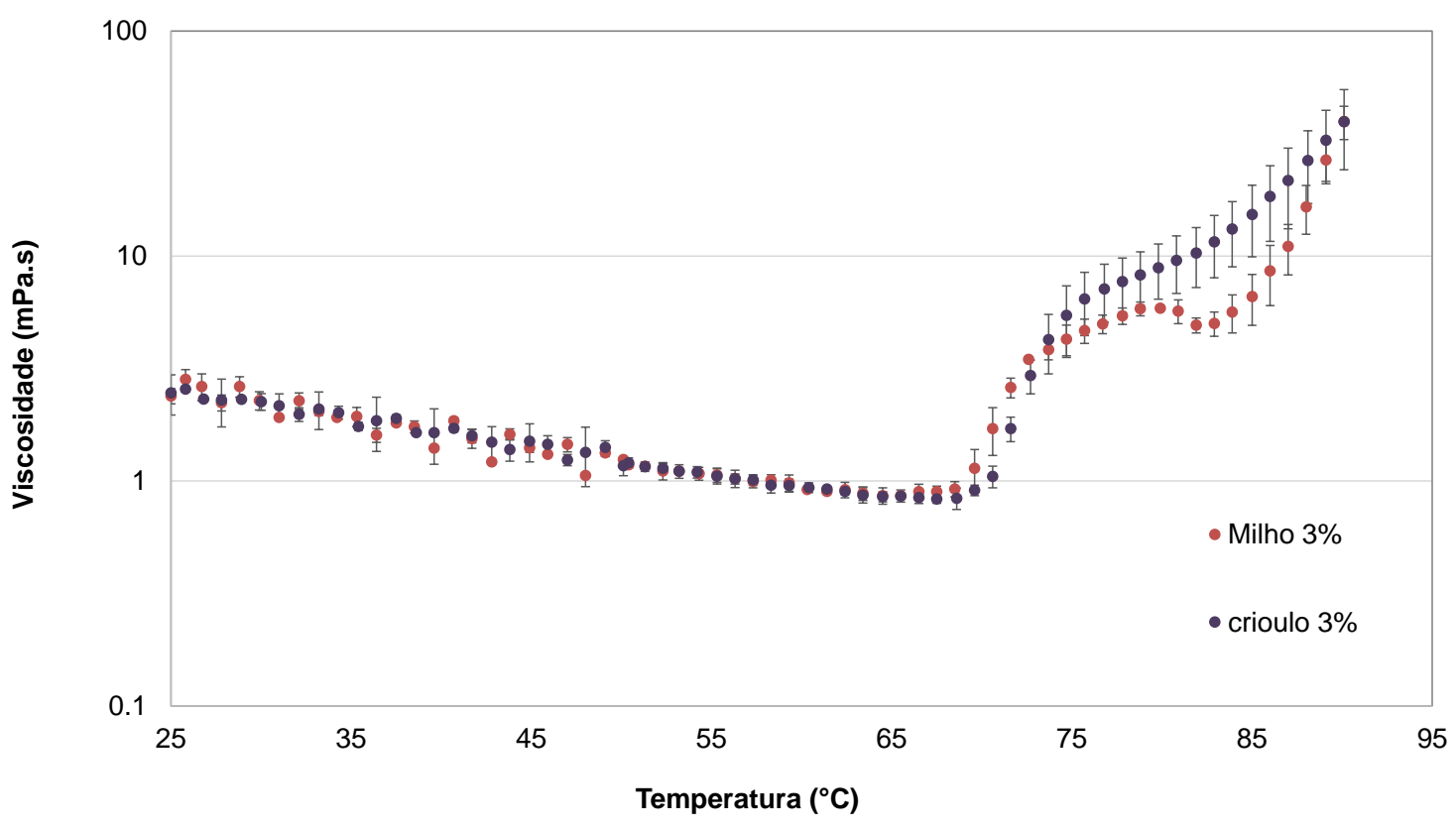

Fonte: LABMULTI.

Figura 6: Gráficos de varredura de frequiência do amido de milho de pipoca (Zea Mays L.) crioulo e de amido de milho comercial ${ }^{\circledR}$ a $25^{\circ} \mathrm{C}$ e deformação de $1 \%$.

A

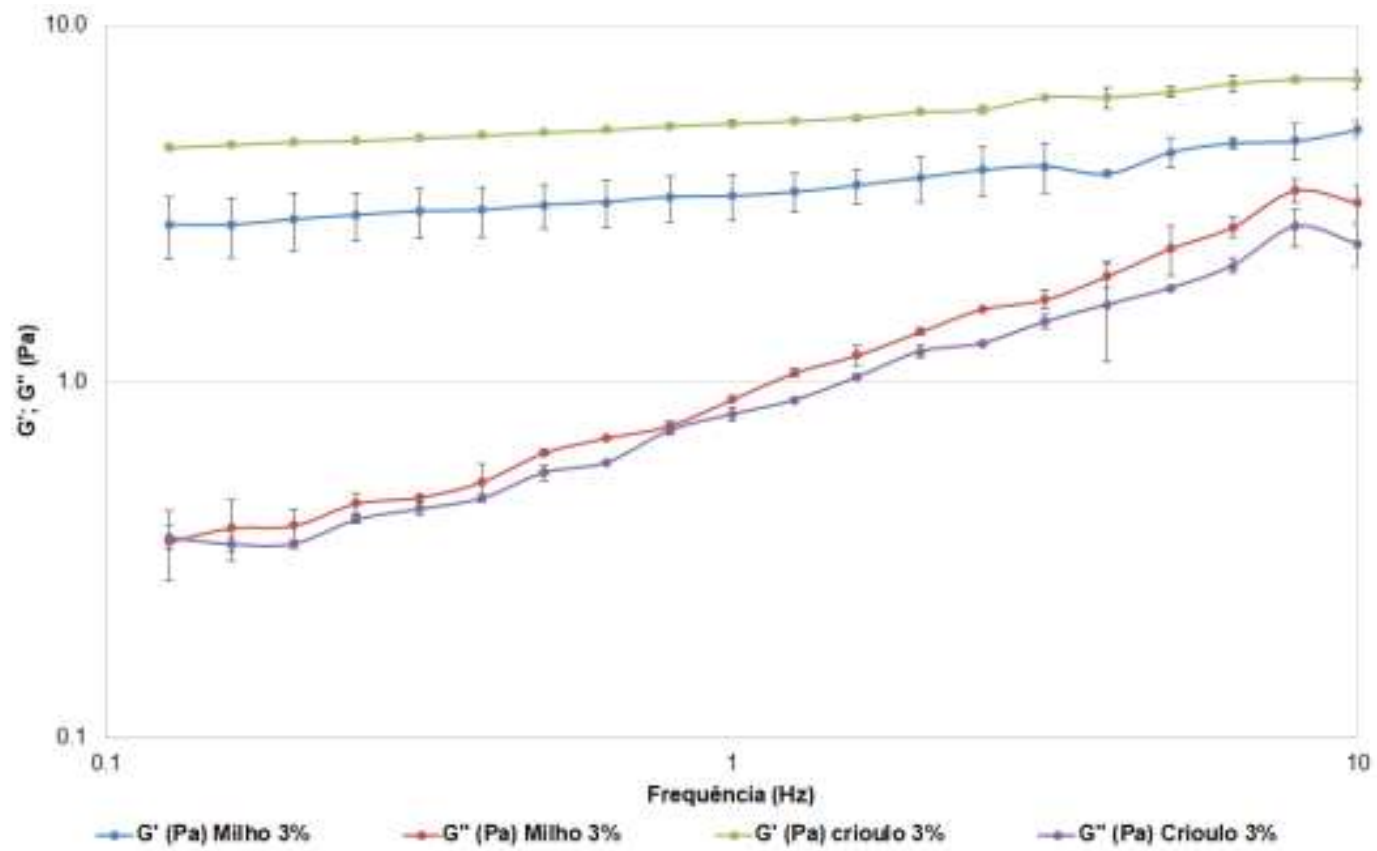




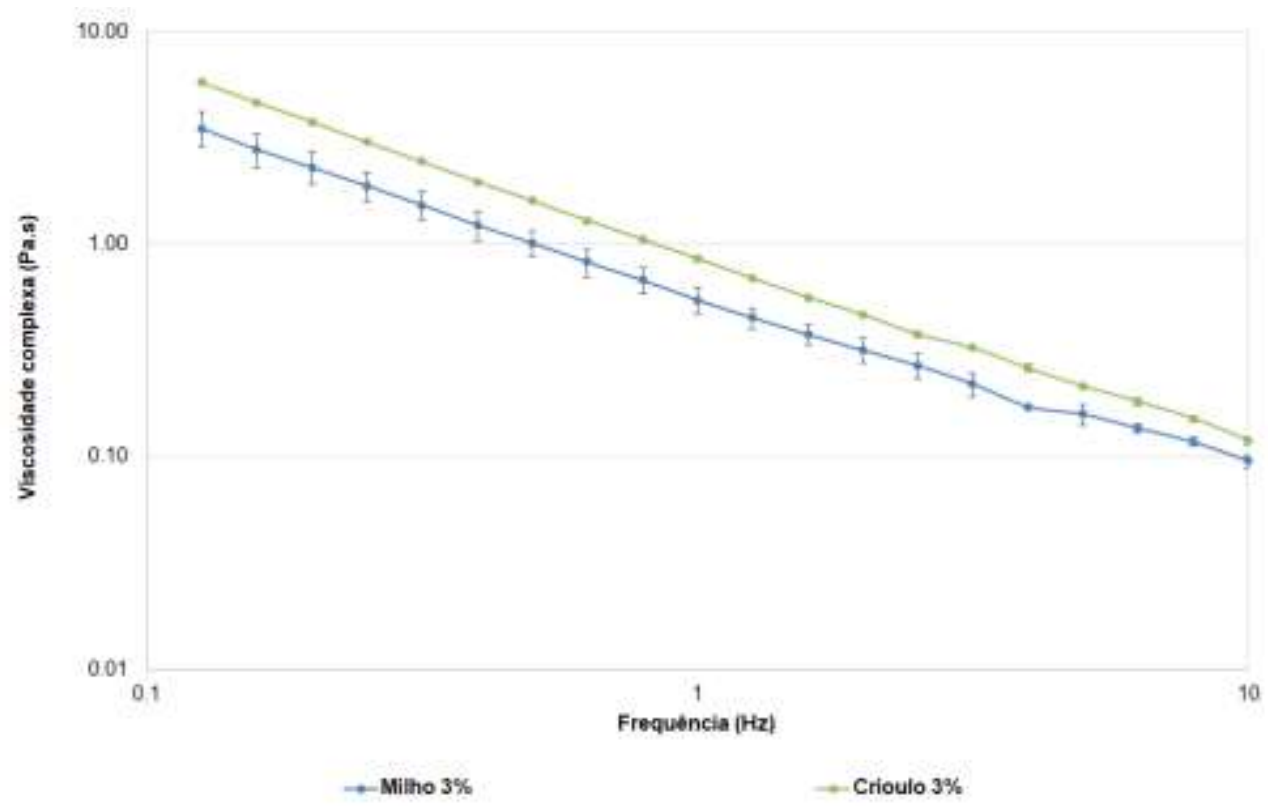

Fonte: Autores.

Figura7: Varredura de temperatura em aquecimento para avaliação da temperatura de gelatinização.

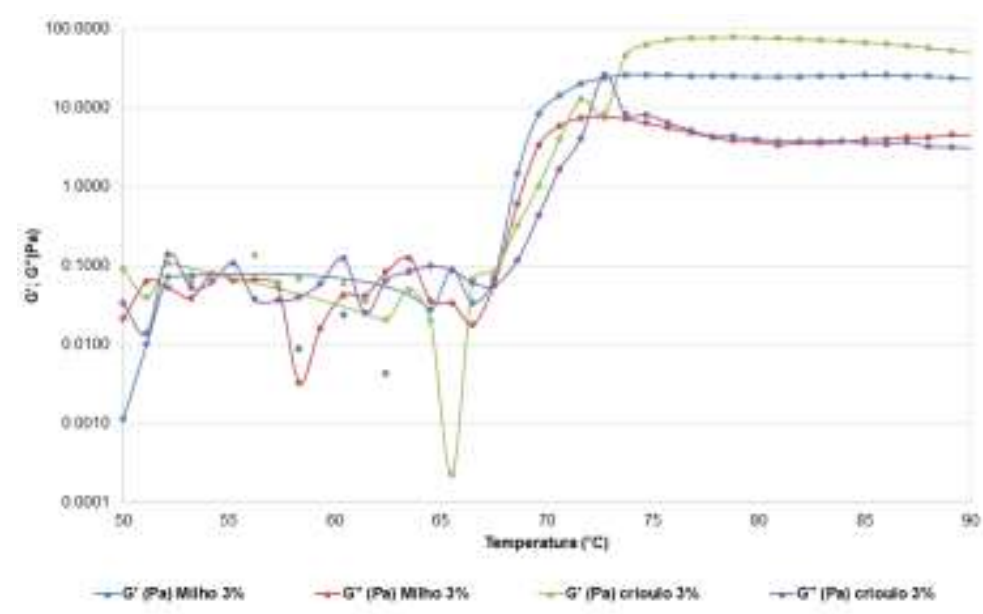

Fonte: Autores.

Em relação à varredura de temperatura em relação a deformação (Fig. 8) sabe-se que ela é usada para observar o comportamento do material submetido a um aumento na deformação e temperatura a freqüências constantes, com a finalidade de determinar os limites do desempenho viscoelástico da dispersão, já que na região viscoelásticas linear (RVL) as propriedades reológicas não são condicionadas à deformação ou ao esforço (Sopade et al., 2004). Para o amido de milho pipoca (Zea Mays L.) crioulo, foi obtido a RVL entre 0 e 11,5\% de deformação. À medida que a temperatura aumenta, a viscosidade também aumenta no intervalo de 17 a 33\% de deformação. Mais uma vez, temos um comportamento típico para dispersões de amido de milho, demonstrando que o amido de milho pipoca crioulo apresenta características favoráveis se empregado na indústria. 
Figura 8: Varredura de temperatura em função de viscoelasticidade complexa.

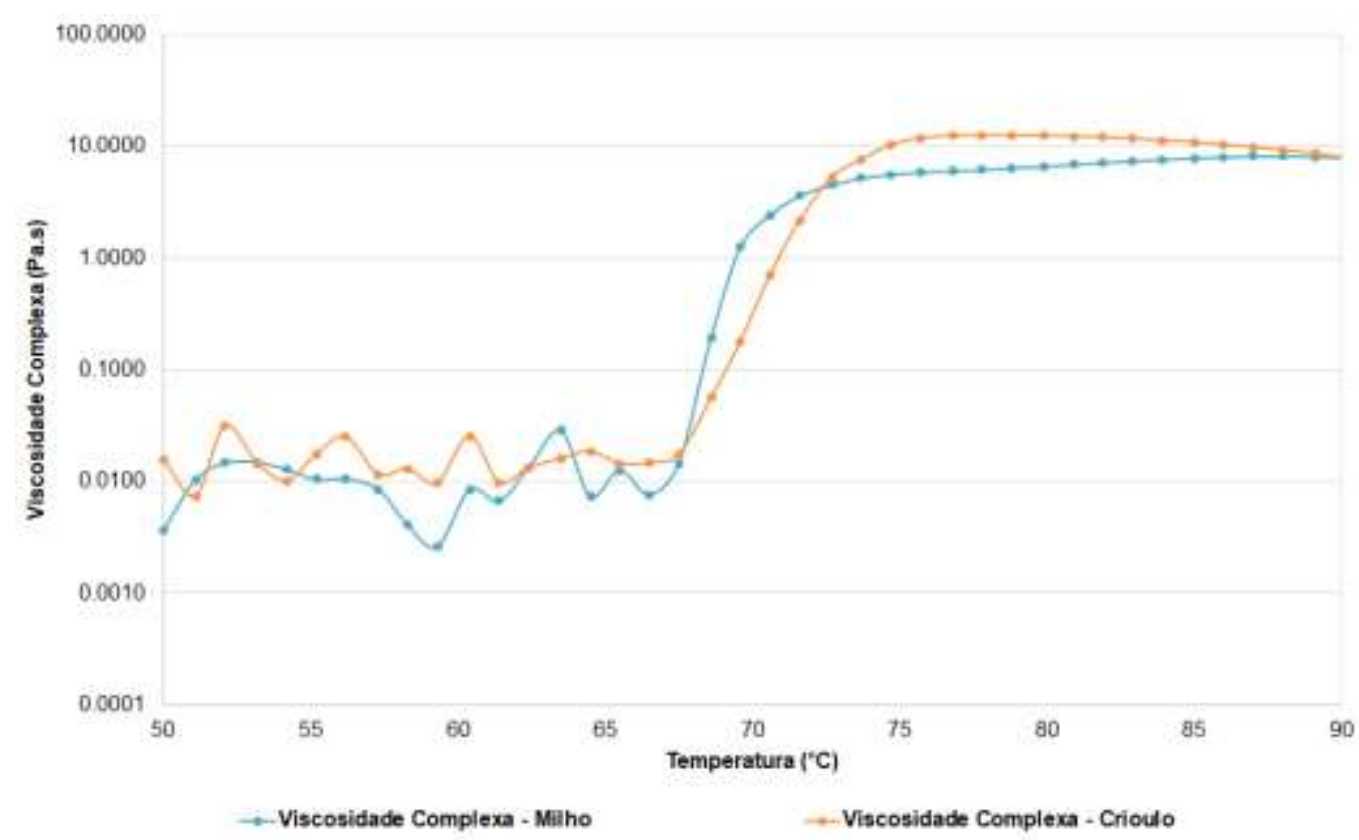

Fonte: Autores.

Em relação ao tempo, as dispersões de amido de milho comercial e de milho pipoca crioulo apresentaram uma cinética distinguível, seguido de um aumento exponencial inicial a 73,5 e 74,6 ${ }^{\circ} \mathrm{C}$, respectivamente (Fig. 9 e 10). $\mathrm{O}$ rápido aumento inicial em $\mathrm{G}^{\prime}$ foi seguido por um platô em $\mathrm{G}^{\prime}$ gerando uma cinética de gelatinização nos dois amidos nas temperaturas citadas. Essa temperatura foi determinada na varredura de temperatura e a temperatura de gelatinização foi determinada em $68,5{ }^{\circ} \mathrm{C}$. Dessa forma, foi realizada a varredura de tempo nesta temperatura para avaliar a cinética de desenvolvimento de estrutura do gel de amido. "Observou-se que não houve variação de G' (módulo elástico) e nem de G" (módulo viscoso) tanto para o amido de milho, quanto para o milho crioulo. Provavelmente, a estrutura do gel já estava estabelecida e em com estabilidade das interações macromoleculares. Nesse caso, o gel tem comportamento elástico (G "> G ').

Figura 9: Varredura de deformação de $1 \%$ a $1 \mathrm{~Hz}$.

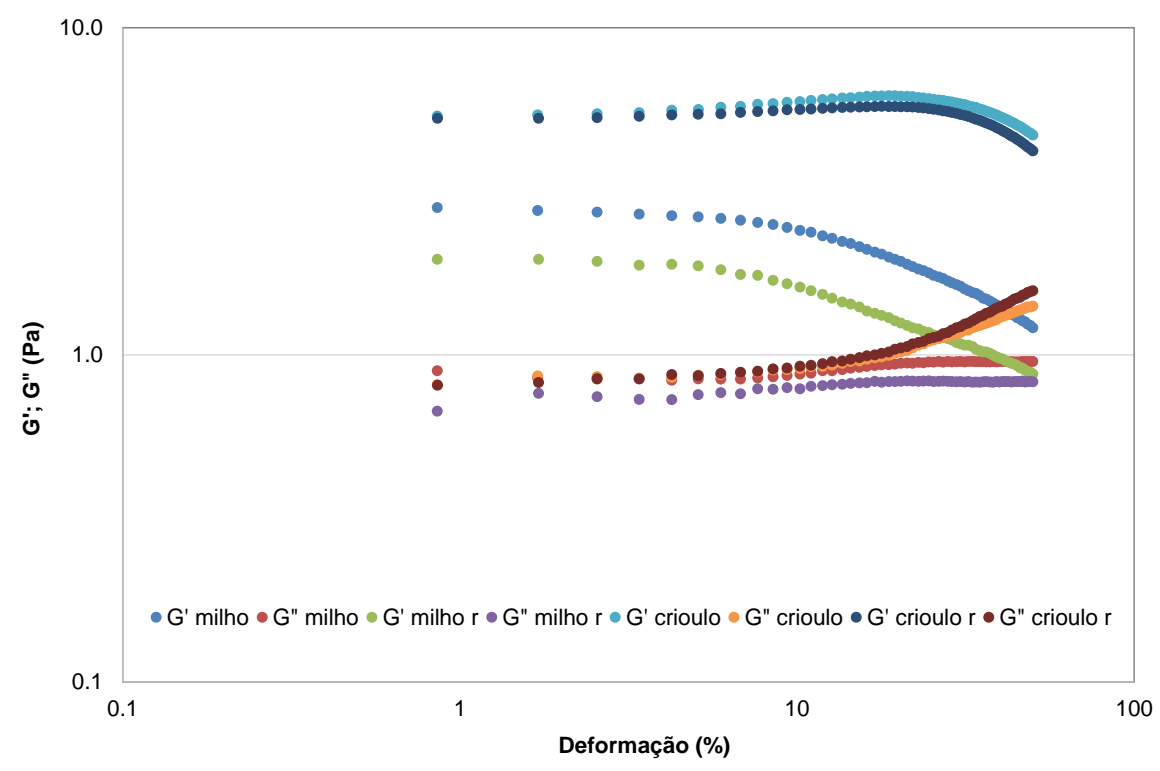

Fonte: Autores. 
Figura 10: Varredura de tempo em temperatura constante.

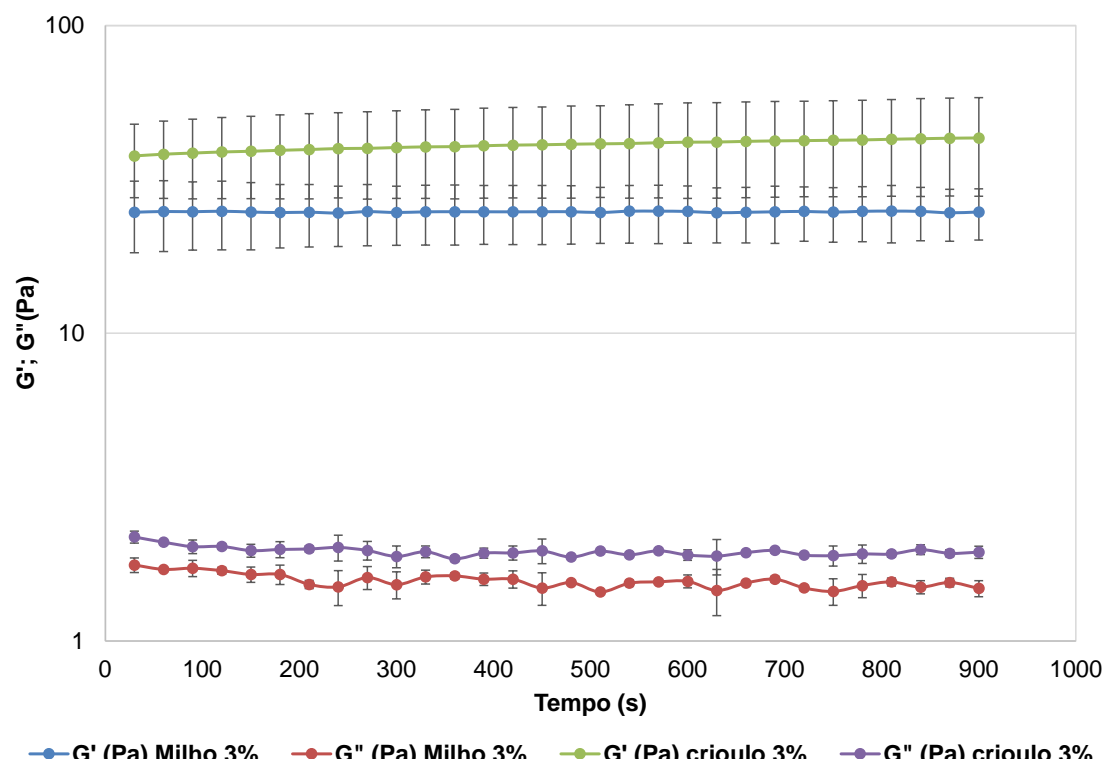

Fonte: Autores.

O tamanho do grânulo é um quesito que influencia os valores do módulo G ', que em um tamanho menor do grânulo de gel de amido, os valores do módulo G' são menores, bem como outros fatores, como morfologia do grânulo, cristalinidade relativa, teor de amilose e amilopectina e traços de outros componentes influenciam a reologia dinâmica do amido (Li \& Zhu, 2018). A importância de um amido formar um gel verdadeiro/elástico é permitir a estruturação de texturas desejadas em alimentos. Pelas propriedades térmicas apresentadas, o amido de milho crioulo, como à sua alta temperatura de gelatinização, poderá ser utilizado em produtos que necessitem de altas temperaturas para serem fabricados, como enlatados, papinhas que passem pelo processo de pasteurização. Em relação à viscosidade, conforme Aprianita et al., (2009), os amidos de alta viscosidade podem ter potencial para aplicações na indústria de alimentos para aumentar o poder de espessamento dos mesmos.

\section{Conclusão}

O rendimento da extração do amido de milho de pipoca (Zea Mays L.) crioulo foi de 6,3\%, sendo bem menor do que o relatado por outros autores. No entanto, o resultado encontrado foi devido à ausência de nenhum reagente químico com o objetivo de manter o caráter natural do amido. Da mesma forma, a extração do amido poder ser facilmente reproduzido por pequenos agricultores da agricultura familiar e indústrias. Suas características e composição proximal são comuns a muitos amidos, mas também inovadora por possuir baixa acidez o que favorece o seu uso para o aumento da viscosidade em outros produtos industrializados.

Sua cor, tendendo mais para tons avermelhados e amarelados (alaranjados), leva a crer que o amido estudado pode ser usado pela indústria sem alterar as características próprias dos produtos que o contenham. No entanto, quando utilizado, isso deve ser verificado através de análises e pesquisas especificas.

Os tamanhos e formas dos grânulos verificados através da MEV justificam seu comportamento viscoelástico e características reológicas. Da mesma forma podem ter contribuído para a sua perda de massa juntamente com os teores de proteína e lipídeos. A concentração de lipídio também foi decisiva na gelatinização do amido do presente estudo. A 
espectroscopia no infravermelho comprovou que o amido de milho crioulo (Zea Mays L.) crioulo comportou-se tipicamente como outros amidos, bem como a sua cristalinidade.

Através dos estudos reológicos podemos concluir que o amido de milho crioulo apresenta comportamento reológico típico, assim como o comportamento viscoelástico, com maior predominância do comportamento elástico ( $G^{\text {' }>G^{\prime}}$ '), podendo ser utilizados em produtos que requeiram altas temperaturas e que possam ter a sua cor como forma de agregar valor. Assim, o cultivo e comercialização desses milhos podem ser estimulados para a obtenção de amidos com esse potencial.Quando novos produtos são criados, os amidos com propriedades específicas e características são utilizados para proporcionar funcionalidade ao alimento. No entanto, essas aplicações podem apresentar algumas limitações que emperram a sua utilização na forma nativa, em determinados produtos, como é o caso do amido de milho crioulo aqui estudado. Esses obstáculos podem ser resolvidos com alterações tanto nas vias química, quanto nas físicas, enzimáticas e mesmo a combinação de diferentes vias, conferindo a este amido propriedades funcionais próprias. Essas alterações permitem "transformar" o amido de acordo com a finalidade que se quer, gerando produtos amiláceos mais específicos e consequentemente mais funcionais do ponto de vista nutricional e também tecnológico. A funcionalidade do amido poderá ser influenciada ou controlada. Propriedades, como textura, volume, consistência, umidade e vida de prateleira dos alimentos são dependentes de suas propriedades físicas e químicas, as quais variam de uma espécie para outra, ou são influenciadas por fatores ecológicos e agronômicos como já relatado. Desta forma, estamos diante de um produto com potencial tecnológico por sua cor e características tecnológicas favoráveis que proporciona seu uso em alimentos para conferir estabilidade e texturas. Por ser de fácil obtenção, já que sua extração é simples e sem o uso de aditivos químicos caros, essa tecnologia pode explorada e replicada por pequenos agricultores e produtores de alimentos já que o rendimento da sua extração não é alto. É mais uma alternativa de fomentar esse nicho além de possibilitar o uso de um produto diferente do que há no mercado mas com potencial tecnologico semelhante.

Mais estudos podem e precisam ser feitos já que os resultados aqui obtidos levam a crer que esse amido podem conter antocianinas e carotenóides o que pode agregar ainda mais valor nutritivo aos alimentos que o contenha. Além disso, pode possibilitar o desenvolvimento de novos produtos como revestimentos comestíveis que podem ser usados para o aumento de vida de prateleira de produtos hortícolas, gerando menos custos aos seus produtores, além de diminuir desperdícios na cadeia produtiva desses produtos.

\section{Referências}

Abimilho. (2021). Associação Brasileira das Indústrias do Milho. Estatísticas de Produção e Consumo Do Milho. https://www.abimilho.com.br/estatisticas

Albano, k. M. (2012). Comportamento reológico de géis de amido de mandioquinha salsa (Arracacia xanthorrhiza B.). Universidade Estadual Paulista “Júlio de Mesquita Filho.

AOAC - Association of Official Analytical Chemists. (2010). Official methods of analysis.

Aprianita, A., Purwandari, U., Watson, B., \& Vasiljevic, T. (2009). Physico-chemical properties of flours and starches from selected commercial tubers available in Australia. International Food Research Journal, 16(4), 507-520.

Araújo, J. M. A. (2004). Qúimica de Alimentos (3rd ed.).

Ascheri, D. P. R., Moura, W. S., Ascheri, J. L. R., \& Carvalho, C. W. P. (2010). Caracterização física e físico-química de rizomas e amido do lírio-do-brejo (Hedychiumcoronarium). PesquisaAgropecuária Tropical, 40(2), 159-166.

Asmeda, R., Noorlaila, A., \& Norziah, M. H. (2016). Relationships of damaged starch granules and particle size distribution with pasting and thermal profiles of milled MR263 rice flour. Food Chemistry, 191, 45-51. https://doi.org/10.1016/j.foodchem.2015.05.095

Association, A. M. S. (2012). AMSA Meat Color Measurement Guidelines: AMSA. In American Meat Science Association. (Issue December).

Belhadi, B., Djabali, D., Souilah, R., Yousfi, M., \& Nadjemi, B. (2013). Three small-scale laboratory steeping and wet-milling procedures for isolation of starch from sorghum grains cultivated in Sahara of Algeria. Food and Bioproducts Processing, 91(3), 225-232. https://doi.org/10.1016/j.fbp.2012.09.008 
Bello-Pérez, L. A., Contreras-Ramos, S. M., Jìmenez-Aparicio, A., \& Paredes-López, O. (2000). Acetylation and characterization of banana (MUSA paradisiaca) starch. Acta Cientifica Venezolana, 51(3), 143-149.

Resolução-RDC no 263, de 22 de setembro de 2005, (2005). https://bvsms.saude.gov.br/bvs/saudelegis/anvisa/2005/rdc0263_22_09_2005.html

Buléon, A., Colonna, P., Planchot, V., \& Ball, S. (1998). Starch granules: Structure and biosynthesis. In International Journal of Biological Macromolecules (Vol. 23, Issue 2, pp. 85-112). https://doi.org/10.1016/S0141-8130(98)00040-3

Candido, L. M., Coelho, J. P. S., Santini, A. W. H., Moreira, W. R., Totou, A. R., \& Rodrigues, R. R. (2017). Influência na Concentração do amido na Gelatinização. 115-123. https://doi.org/10.5151/2594-357x-30363

Cargill. (2019). Relatório Anual Cargill 2018/2019. https://www.cargill.com/static/brazil-annual-report/2018-2019/pt/index.html

Castro, D. S. de. (2019). Extração e Utilização do amido do endocarpo da pitomba na elaboração de Catchup e no desenvolvimento de revestimentos comestíveis. Universidade Federal de Campina Grande.

Cavalcanti, M. T., Silva, V. C., Costa, T. S., Florêncio, I. M., \& Florentino, E. R. (2011). Obtenção do amido do endocarpo da manga para diversificação produtiva na indústria de alimentos. Revista Verde de Agroecologia e Desenvolvimento Sustentável, 6(5), 80-83.

Cheim, L. M. G., Costa, F. M., Silva, N. C. de A., Caneppele, C., Cesar, A. L. T. M. de S., Rossignoli, P. A., \& Faria, A. M. de M. (2021). Characterization of the Seeds of a Landrace Popcorn (Zea mays L. subsp. mays) Cropped in an Organic System via Family Farming. Research, Society and Development, 10(4).

Correia, P. R., Nunes, M. C., \& Beirão-da-Costa, M. L. (2012). The effect of starch isolation method on physical and functional properties of Portuguese nuts starches. I. Chestnuts (Castanea sativa Mill. var. Martainha and Longal) fruits. Food Hydrocolloids, 27(1), 256-263. https://doi.org/10.1016/j.foodhyd.2011.05.010

Correia, P. R., Nunes, M. C., \& Beirão-da-Costa, M. L. (2013). The effect of starch isolation method on physical and functional properties of Portuguese nut starches. II. Q. rotundifolia Lam. and Q. suber Lam. acorns starches. Food Hydrocolloids, 30(1), 448-455. https://doi.org/10.1016/j.foodhyd.2012.06.014

Diamantino, V. R. (2013). Efeito da adição de amido de milho ceroso em queijo minas frescal com teor reduzido de gordura. Unesp.

Franco, V. A., Silva, F. A., Miranda, B. M., \& Pádua, D. L. (2018). Propriedades reológicas e composição proximal da farinha de arroz e farinha de batatadoce.Científic@ - Multidisciplinary Journal, 5(3), 113-124. https://doi.org/10.29247/2358-260x.2018v5i3.p113-124

Fringant, C., Desbrières, J., \& Rinaudo, M. (1996). Physical properties of acetylated starch-based materials: Relation with their molecular characteristics. Polymer, 37(13), 2663-2673. https://doi.org/10.1016/0032-3861(96)87626-9

García-Gavín, J., Parente, J., \& Goossens, A. (2012). Allergic contact dermatitis caused by sodium metabisulfite: A challenging allergen. A case series and literature review. In Contact Dermatitis (Vol. 67, Issue 5). https://doi.org/10.1111/j.1600-0536.2012.02135.x

Gwirtz, J. A., \& Garcia-Casal, M. N. (2014). Processing maize flour and corn meal food products. Annals of the New York Academy of Sciences, 1312(1), 66-75. https://doi.org/10.1111/nyas.12299

Ha, M. A., Jarvis, M. C., \& Mann, J. I. (2000). A definition for dietary fibre. In European Journal of Clinical Nutrition (Vol. 54, Issue 12, pp. 861-864). https://doi.org/10.1038/sj.ejcn.1601109

Ji, Y., \& Yu, J. (2018). In vitro digestion and physicochemical characteristics of corn starch mixed with amino acid modified by heat-moisture treatment. Food Hydrocolloids, 77, 720-725. https://doi.org/10.1016/j.foodhyd.2017.11.013

Jiranuntakul, W., Puttanlek, C., Rungsardthong, V., Puncha-Arnon, S., \& Uttapap, D. (2011). Microstructural and physicochemical properties of heat-moisture treated waxy and normal starches. Journal of Food Engineering, 104(2), 246-258. https://doi.org/10.1016/j.jfoodeng.2010.12.016

Julyana, R., Devos, B., Pessutto, I., Oro, T., \& Gutkoski, C. (2018). Extração e Caracterização de amidos de milho. Simpósio de Alimentos. https://www.upf.br/_uploads/Conteudo/simposio-sial-anais/2018/ciencia/c-51.pdf

Kaur, A., Shevkani, K., Katyal, M., Singh, N., Ahlawat, A. K., \& Singh, A. M. (2016). Physicochemical and rheological properties of starch and flour from different durum wheat varieties and their relationships with noodle quality. Journal of Food Science and Technology, 53(4), 2127-2138. https://doi.org/10.1007/s13197-016-2202-3

Leonel, M. (2007). Análise da forma e tamanho de grânulos de amidos de diferentes fontes botânica. Ciência e Tecnologia de Alimentos, $27(3)$, 579-588.

Li, G., \& Zhu, F. (2018). Effect of high pressure on rheological and thermal properties of quinoa and maize starches. Food Chemistry, 241, 380-386. https://doi.org/10.1016/j.foodchem.2017.08.088

Lutz, I. A. (2008). Normas analíticas do Instituto Adolfo Lutz. Métodos físicos-quimicos para análise de Alimentos. In Livro sobrre análise de alimentos Insitituo Adolfo Lutz. https://wp.ufpel.edu.br/nutricaobromatologia/files/2013/07/NormasADOLFOLUTZ.pdf

Macdougal, D. . (1994). Quality Attributes and their Measurement in Meat, Poultry and Fish Products. In Quality Attributes and their Measurement in Meat, Poultry and Fish Products. https://doi.org/10.1007/978-1-4615-2167-9

Mahmood, K., Kamilah, H., Shang, P. L., Sulaiman, S., Ariffin, F., \& Alias, A. K. (2017). A review: Interaction of starch/non-starch hydrocolloid blending and the recent food applications. In Food Bioscience (Vol. 19, pp. 110-120). https://doi.org/10.1016/j.fbio.2017.05.006

Marques, R. C. D. (2016). Estudo físico químico, microbiológico e tecnológico de coprodutos da industrialização de milho e aproveitamento alimentar a partir da elaboração de massas alimentícias. Universidade Federal de Goiás. 
Moritz, A. R. (2011). Existe cor em nossas vidas. A colorimetria aplicada em nossos dias. In BrasEq (1st ed.).

Nguyen, Q. D., Jensen, C. T. B., \& Kristensen, P. G. (1998). Experimental and modelling studies of the flow properties of maize and waxy maize starch pastes. Chemical Engineering Journal, 70(2), 165-171. https://doi.org/10.1016/S1385-8947(98)00081-3

Oyeyinka, S. A., \& Oyeyinka, A. T. (2018). A review on isolation, composition, physicochemical properties and modification of Bambara groundnut starch. In Food Hydrocolloids (Vol. 75, pp. 62-71). https://doi.org/10.1016/j.foodhyd.2017.09.012

Pavlovic, S., \& Brandao, P. R. G. (2003). Adsorption of starch, amylose, amylopectin and glucose monomer and their effect on the flotation of hematite and quartz. Minerals Engineering, 16(11), 1117-1122. https://doi.org/10.1016/j.mineng.2003.06.011

Piergiovanni, P. R., \& Jarboe, J. H. (2016). Experiments for a unit operations in food engineering course. ASEE Annual Conference and Exposition, Conference Proceedings, 2016-June. https://doi.org/10.18260/p.26836

Riley, C. K., Wheatley, A. O., \& Asemota, H. N. (2006). Isolation and characterization of starches from eight Dioscorea alata cultivars grown in Jamaica. African Journal of Biotechnology, 5(17), 1528-1536. https://doi.org/10.4314/ajb.v5i17.43151

Saliba Rodrigues, H. C., Bevilacqua, C. B., Bahry, C. A., Ramirez Monzon, D. L., Viana, T. P., Zimmer, P. D., \& Reis Fagundes, P. R. (2014). Aplicação de índice de estresse para a tolerância ao frio no desenvolvimento inicial de cultivares de arroz. Científica, 42(3), 258. https://doi.org/10.15361/1984$5529.2014 \mathrm{v} 42 \mathrm{n} 3 \mathrm{p} 258-264$

Singh, N., Singh, S., Isono, N., Noda, T., \& Singh, A. M. (2009). Diversity in amylopectin structure, thermal and pasting properties of starches from wheat varieties/lines. International Journal of Biological Macromolecules, 45(3), 298-304. https://doi.org/10.1016/j.ijbiomac.2009.06.005

Song, T. W. (2004). Fenômenos de Transporte I. In Apostila para a disciplina de graduação (p. 150p).

Sopade, P. A., Halley, P. J., \& Junming, L. L. (2004). Gelatinisation of starch in mixtures of sugars. I. Dynamic rheological properties and behaviours of starch-honey systems. Journal of Food Engineering, 61(3), 439-448. https://doi.org/10.1016/S0260-8774(03)00153-5

Sriburi, P., Hill, S. E., \& Mitchell, J. R. (1999). Effects of L-ascorbic acid on the conversion of cassava starch. Food Hydrocolloids, 13(2), 177-183. https://doi.org/10.1016/S0268-005X(98)00080-0

Sriburi, Pensiri, \& Hill, S. E. (2000). Extrusion of cassava starch with either variations in ascorbic acid concentration or pH. International Journal of Food Science and Technology, 35(2), 141-154. https://doi.org/10.1046/j.1365-2621.2000.00360.x

Teixeira, B. S. (2016). Características de amidos processados pela radiação ionizante. In Universidade De São Paulo. Universidade’de’São’Paulo.

Trire, R. M. S., Simão, R. A., Araújo, P. J. G., \& Anchete, C. A. (2004). Redução da hidrofilicidade de filmes biodegradáveis a base de amido por meio de polimerização por plasma. Polímeros: Ciência e Tecnologia, 14, 57-62.

Uenojo, M., Maróstica, M. R., \& Pastore, G. M. (2007). Carotenóides: Propriedades, aplicações e biotransformação para formação de compostos de aroma. In Quimica Nova (Vol. 30, Issue 3, pp. 616-622). https://doi.org/10.1590/S0100-40422007000300022

Universidade Estadual de Campinas UNICAMP. (2011). Tabela brasileira de composição de alimentos. In Tabela brasileira de Composição de Alimentos - TACO (4a). http://www.unicamp.br/nepa/taco/

Vallès-Pàmies, B., Barclay, F., Hill, S. E., Mitchell, J. R., Paterson, L. A., \& Blanshard, J. M. V. (1997). The effects of low molecular weight additives on the viscosities of cassava starch. Carbohydrate Polymers, 34(1-2), 31-38. https://doi.org/10.1016/S0144-8617(97)00094-5

Wang, L., Xu, J., Fan, X., Wang, Q., Wang, Q., ZHANG, Y., Cui, L., Yula, J., \& Yu, Y. (2016). Effect of disaccharides of different composition and linkage on corn and waxy corn starch retrogradation. Food Hydrocolloids, 61(1), 531-536.

Wang, Y. J., Sheau, W. C., \& Yang, W. (2006). Effect of pericarp removal on properties of wet-milled corn starch. Cereal Chemistry, 83(1), 25-27. https://doi.org/10.1094/CC-83-0025

Weber, F. H., Collares-Queiroz, F. P., \& Chang, Y. K. (2009). Caracterização físico-química, reológica, morfológica e térmica dos amidos de milho normal, ceroso e com alto teor de amilose. Ciência e Tecnologia de Alimentos, 29(4), 748-753. https://doi.org/10.1590/s0101-20612009000400008

Wolkers, W. F., Oliver, A. E., Tablin, F., \& Crowe, J. H. (2004). A Fourier-transform infrared spectroscopy study of sugar glasses. Carbohydrate Research, 339(6), 1077-1085. https://doi.org/10.1016/j.carres.2004.01.016

Xiao, H., Lin, Q., Liu, G. Q., Wu, Y., Tian, W., Wu, W., \& Fu, X. (2011). Physicochemical properties of chemically modified starches from different botanical origin. Scientific Research and Essays, 6(21), 4517-4525. https://doi.org/10.5897/sre11.618

Yonemoto, P. G. (2006). Efeito do tamanho dos grânulos nas características estruturais e físicoquímicas do amido de trigo. Universidade Estadual Paulista.

Zhu, J., Zhang, S., Zhang, B., Qiao, D., Pu, H., Liu, S., \& Li, L. (2017). Structural features and thermal property of propionylated starches with different amylose/amylopectin ratio. International Journal of Biological Macromolecules, 97, 123-130. https://doi.org/10.1016/j.ijbiomac.2017.01.033

Zhuang, H., Tang, N., \& Yuan, Y. (2013). Purification and identification of antioxidant peptides from corn gluten meal. Journal of Functional Foods, 5(4), 1810-1821. https://doi.org/10.1016/j.jff.2013.08.013 